\title{
التصنيف الائتماني لوكالة فيتش ودوره في منح القروض وجذب الودائح دراسة تحليلية في مصرف الأهلي المتحد
}

أ.م.د. حيلر جواد المرشدي

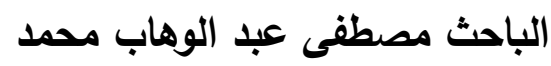

كلية الادارة والاقتصاد/ جامعة الكوفة

المقدمة

إن التطورات السريعة التي تشهدها الاسواق العالمية وحجم المعاملات الكبير كذلك حجم الصفقات

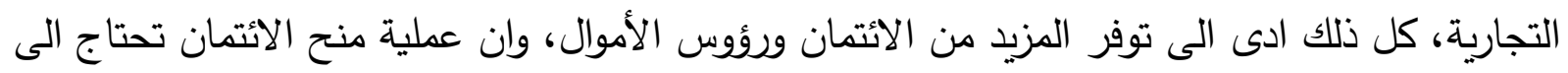
معلومات سريعة ودقيقة، وبما انه في الوقت الحاضر قد تعددت وتطورت انشطة المقترضين، فبذلك الكان نلاحظ ان البيانات المالية لم تعد كافية وحدها لاتخاذ قرار الائتمان من قبل مانحي القروض في منح القرض من عدمه. حيث نجد ان هناك حاجة لسد الفجوة بين المتعاملين من حيث المعلومات ، هذا بدوره

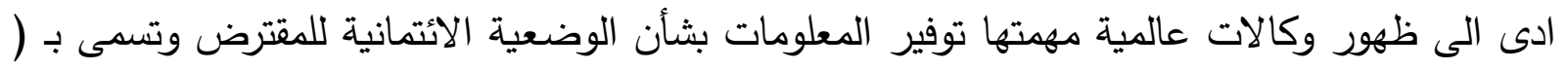

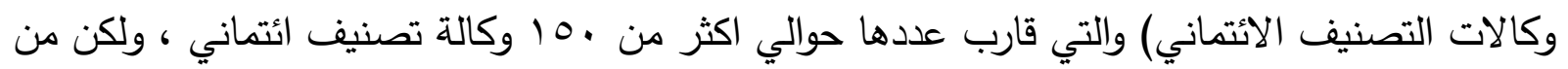

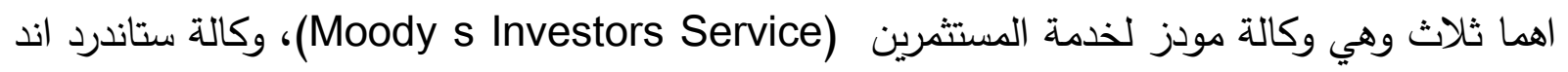
بورز (Standard \& Poor)، وكالة فيتش للتصنيف (Fitch Ratings) ، ومن هذا المنطلق اصبح

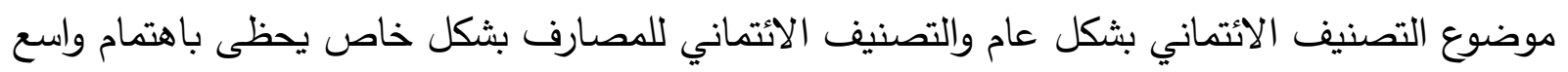

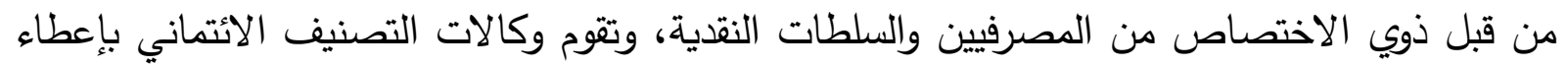

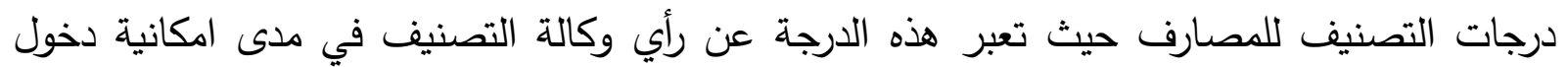
المصرف في صعوبات مالية، اذ يهدف التصنيف في جوهره في الكثف عن الجدارة الائتمانية للجهة المقترضة وتحديد مدى قدرتها على الوفاء بالتزاماتها المالية عند الاستحقاق. وتعتمد وكالات التصنيف 
الائتماني على مزيج من المدخلات الكمية والكيفية التحليلية لأداء المؤسسة المعنية فقد جاءت هذه

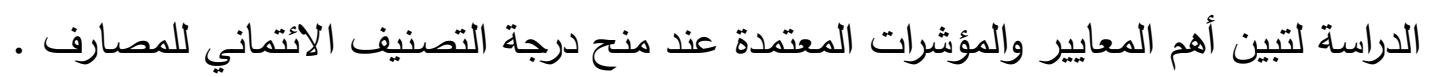
يحاول البحث الحالي تحديد دور التصنيف الائتماني، بوصفه متغيراً مستقلا في منح القروض وجذب الهن

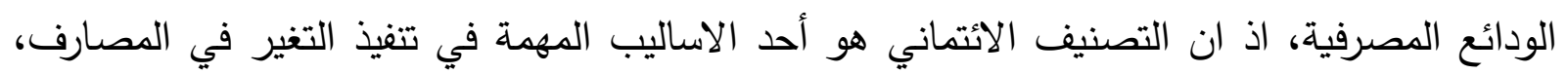
لأنه من المكن ان يساعد المصارف على تحقيق ميزة تنافسية . كما وتحددت مشكلة البحث عن طريق استعراض مجموعة من الحقائق الاكاديمية من اجل تحديد الفجوة

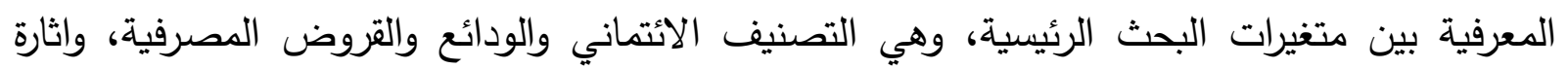
مجموعة من التساؤلات التي تستفهم حول طبيعة العلاقة بين هذه المتغيرات. وإن هدف الدراسة الحالية هو بيان العلاقة بين متغيراتها الأساسية، ولتحقيقه تم رسم المخطط الفرلئهي.

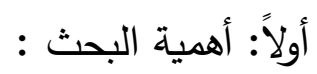

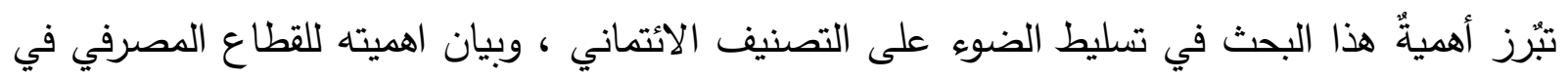
ظل غياب الدراسات التي تعنى بالتصنيف الائتماني للمصارف ، وتقوم عملية التصنيف الأتماني بدورها

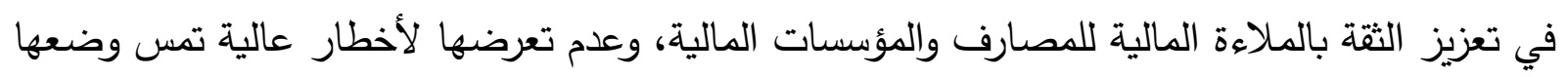

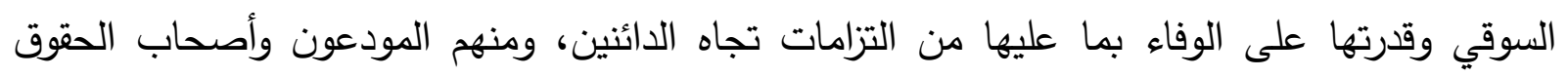
بوجه عام، ومن هنا فإن عملية التصنيف الائماني في غاية الأهمية وخصوصاً بعد أن تزايد الإعلان

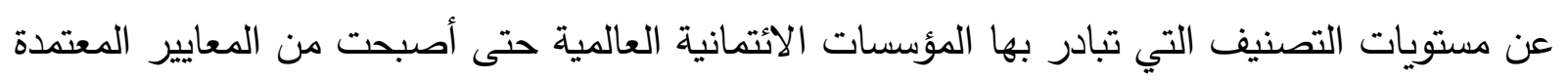

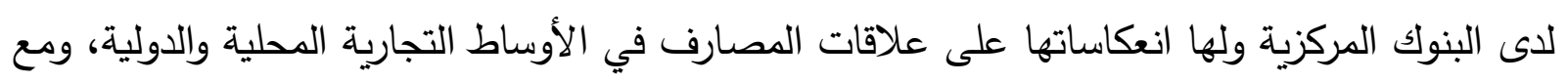

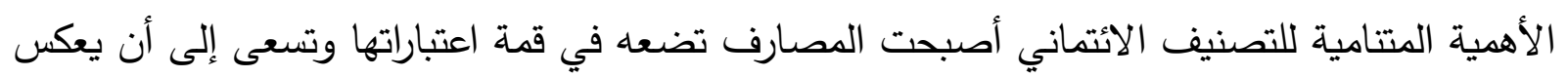
التصنيف سلامة أحوالها المالية ، بل هناك من يجعل التصنيف إحدى الوسائل الدعائية الى حد ما الألى ولاسيما مع تزايد الحاجة الى ادوات تساعد على اتخاذ القرارات المتعلقة بالإقراض ، فضلايلا عن تحليل 
درجة التصنيف الائتماني التي حصلت عليها المصارف عينة البحث من وكالة (فيتش) وكيفية الحصول عليها . ع ثانيا: مشكلة البحث: تعد عملية التصنيف الائتماني واحدة من اهم مؤشرات المخاطرة الائتمانية وذلك لان نتائج التصنيف توضح قدرة المقترض على الوفاء بالتزاماته المالية في الوقت المحدد ، وعند تحليل قدرة المصرف الهرف عينة البحث على الوفاء بالتزاماته نلاحظ انه حصل على درجات تصنيف مختلفة وهذه الدرجة اولدت عدة الوناء

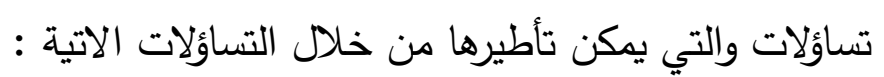

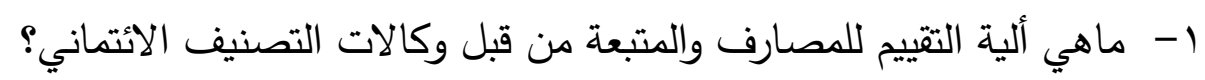
ץ- هل هناك دور للتصنيف الائتماني في منح القروض وجذب التهن الودائع? ثالثا: أهداف البحث:

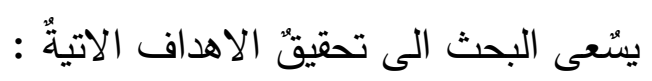
ا ـ توضيح ماهية التصنيف الائتماني وأنواعه.

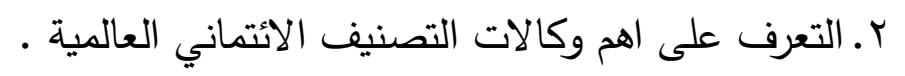

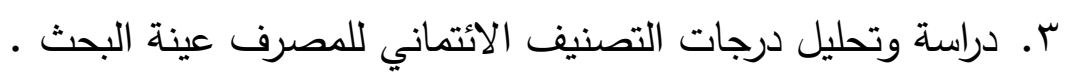

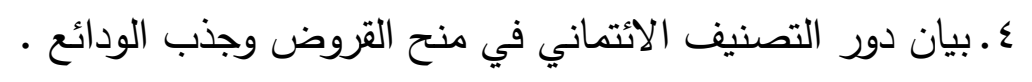
رابعا: فرضية البحث:

إن فرضية البحث هي عبارة عن تخمينات ذكية غير مؤكدة لكنها ممكنة الاختبار ، وان البحث الحالي يتكون من فرضية رئيسة واحدة وهي " هنالك دور للتصنيف الأيتماني في منح القروض وجني مونب الودائع خامسا: منهجية البحث من فرضه استعمل البحث الحالي المنهج الوصفي التحليلي في اختبار فرضياته من خلال دراسة الارتباط والتأثير

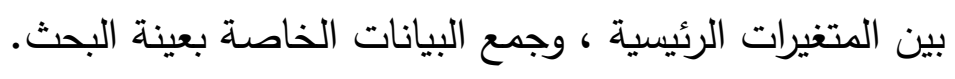


كما استخدم البحث الحالي عدد من الاساليب والادوات الاحصائية و منها الآتي: 1- الارتباط باستعمال معامل ارتباط بيرسون لمتغيرات الكمية .

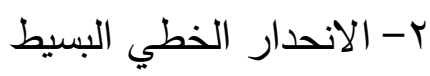

(f)

(t) ع- اختبار معنوية

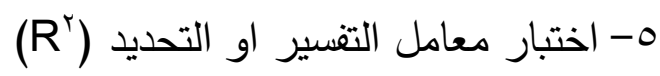

(P) اختبار

المبحث الأول: الاسس النظرية التصنيف الائتماني:

مفهوم التصنيف الائتماني:

وضع العديد من الكتاب والباحثين في مجال التصنيف الائتماني عدة مفاهيم للتصنيف الائتماني هو تقييم الجدارة الائتمانية على اساس التوقعات او تتبؤات تستند على رأي وكالة التصنيف الائتماني لكيفية

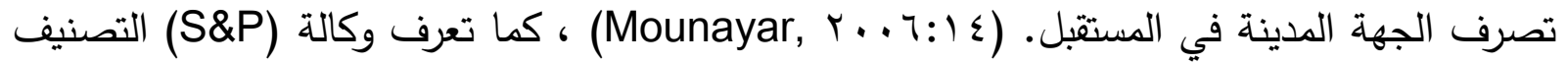
الائتماني بانه الدرجة التي تعبر عن رأي وكالة التصنيف الائماني بالمقدرة المالية والرغبة في الدفع

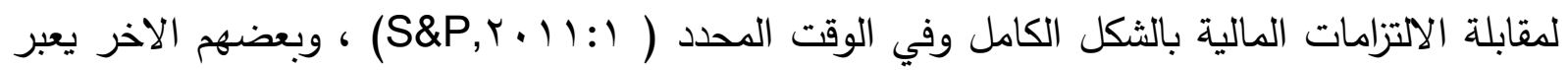
عن التصنيف الائتماني (الجدارة الائتمانية التي يتم اعدادها على اساس التتبؤات والتوقعات .(Mounayar, Y.. . $: 1 \leqslant)$

ويعول كثيرا على درجة التصنيف الائتماني التي تمنحها وكالات التصنيف، بخاصة الحكومات والمؤسسات المالية المصرفية في توقع حدوث مخاطر عدم الدفع بناء على معايير كمية ونوعية، إذ أصبحت أسواق رأس مال حساسة لدرجات التصنيف الائتماني التي تصدرها وكالات التصنيف الائتماني، ذلك أنها تئثر في قدرة الثركات والدول عمى الدخول إلى أسواق رأس المال الدولية والحصول على

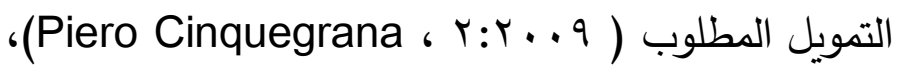


كما و ان الهدف الرئيس للتصنيف الأتتماني هو تقديم المعلومات للمستثمرين ومساعدتهم على تحديد الاحتمال النسبي لخسارة اموالهم على استثماراتهم اي ان التصنيف الائتماني يعد بمثابة مؤشر للمخاطرة

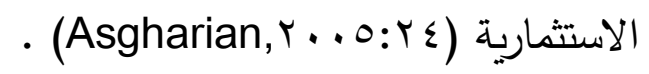
وكالات التصنيف الأيتماني كما يمكن تعريفها على انها مؤسسات تتولى تصنيف وتتقيط خطر مؤسسة ما بقصد اعلام تلك المؤسسة الخاضعة للتصنيف، وكذلك مختلف المتعاملين والمستثمرين الذين يرغبون في شراء او تملك الاوراق المالية التي تقوم بطرحها تلك المؤسسة بمدى قدرتها على الوفاء بالتزاماتها المالية في الآجال المحددة .(Ilanah Jospè et autre ، Y I Y : Y 1 ) ظهرت عدة وكالات تصنيف ائتماني منها المحلية والاقليمية والعالمية والتي اغلبها هي شركات مساهمة خاصة تحصل على ايراداتها من الجهات طالبة التصنيف ، واهم تلك الوكالات هي وكالة ومقرها الولايات المتحدة ، واحتكرت هذه الوكالة التصنيف الأتتماني السيادي (Standard \&Poor)

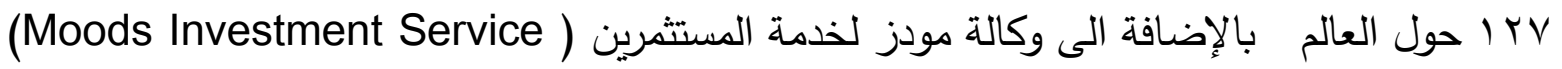

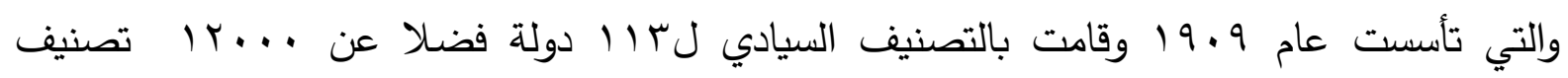

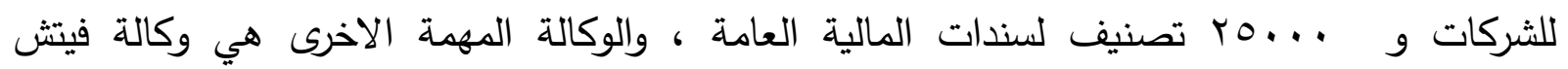
والتي تأسست عام سا (9itch Rating) المثال ، تستند تصنيفاتها على احتمال التخلف عن السداد في المقابل ، تستند Moody's إلى تصنيفاتها

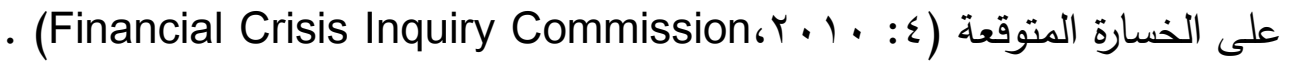
و تبني وكالات التصنيف الائتماني تصنيفاتها الائتمانية على اساس عنصري المخاطرة و الأمان، وهذه تتحدد من خلال مدى قدرة الحكومة على الوفاء بالتزاماتها المالية، وقد اعتمدت وكالات التصنيف الائتماني نوعين من مستوى المخاطر الائتمانية هما درجة الاستثمار ودرجة المضاربة (r: (Bahena) 
التصنيف الائتماني للمصارف:

تمثل التصنيفات الائتمانية للمصارف حكم محلي الائتمان على قدرة المصرف على الوفاء بالتزاماته

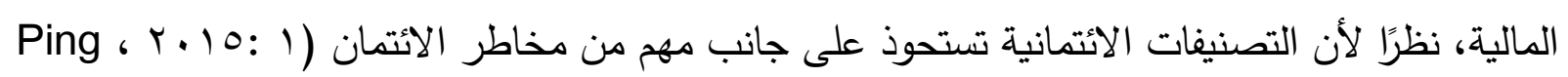

(Lin

خطوات التصنيف الائتماني للمصارف: عندما يقدم المصرف طلبا لوكالة التصنيف الائتماني من أجل الحصول على درجة تصنيف ائتماني، فإن

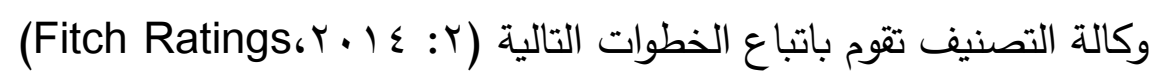

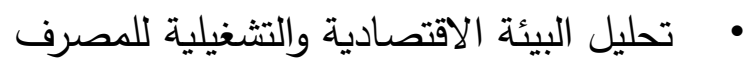

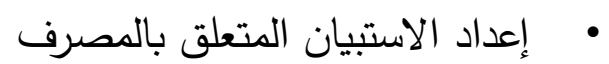

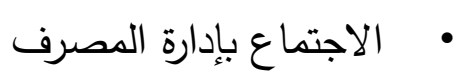

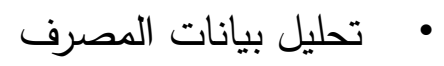
• اختيار النموذج المناسب لإجراء التصنيف الائتماني • اعداد مسودة التقرير • اجتماع لجنة الائتمان وتحديد درجة التصنيف الائتماني • نشر درجة التصنيف الائتماني • اجراء التعديل على مسودة التقرير وتوزيعها على لجنة الائتمان 


\section{التصنيف الائتطاني لوكالة فيتش ودوره في منح القروض وجذب الودائع}

جدول (1) درجات التصنيف الائتماني للمصارف

$$
\text { درجات التصنيف الائتماني للمصارف }
$$

أعلى جودة وأعلى درجة من الاستقرار المالي في المستقبل ضمن بيئة تثغيلية مستقرة ومتوقعة جدا ، المصرف قوي جدا.

جودة قوية ودرجة جيدة من الاستقرار المالي في المستقبل ضمن بيئة تشغيلية مستقرة ومتوقعة جدا ، المصرف قوي .

تصنيف مقبول ومناسب لجودة الائتمان والاستقرار المالي ضمن بيئة تشغيلية مستقرة ومتوقعة ،والمصرف في وضع مناسب . تصنيف متواضع من الجودة والاستقرار المالي في المتتبل ذلك أن المصرف يملك عددا من نقاط القوة الداخلية أو الخارجية ومنها فروع مصرفية ضعنية لفيفة، أو بيانات مالية

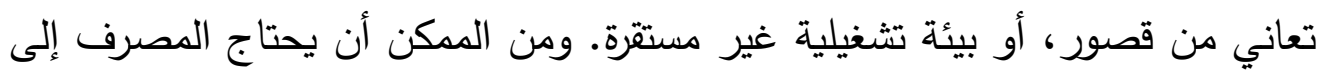

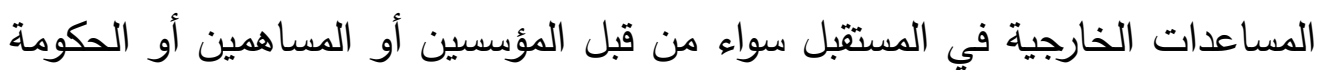
او من جهات أجنبية.

تصنيف ضعيف لجودة الائتمان ولدرجة الاستقرار المالي ن المصرف لديه مخاطر مرتفعة، وهناك احتمالية حاجة المصرف الى الدعم والمساعدة الخارجية او انه سيحتاجها فعلا، ويرجع سبب ذلك الى عدة امور منها : _ فروع المصرف ضعيفة جدا _ البيانات المالية سيئة _ بيئة تثغيلية غير مستقرة •

وتشير الى ان المصرف قد دخل في حالة العجز عن السداد او انه سيدخل في حالة العجز اذا لم يتلق الدعم الخارجي من الحكومة او صناديق الأتثمان او عملية احتواء من طرف مؤسسة مالية اخرى او تمويل من حملة الاسهم والمالكين . 


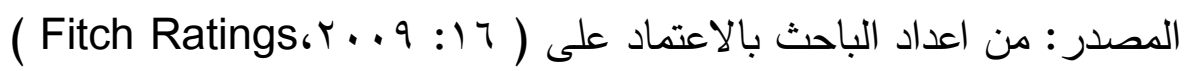
كما تضيف وكالة فيتش للتصنيف الأيتماني (+) او (-) على يمين درجة التصنيف التي هي ادنى من A والاعلى من E للدلالة على الجودة الائمانية للمصارف التي تقع في النهاية العليا او الدنيا لدرجة

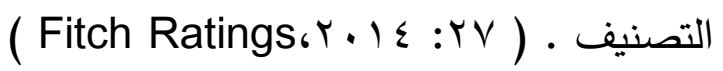

معايير تصنيف المصارف حسب وكالة فيتش: تصنيفات القدرة على الاستمرار : تصعايز

يتم تعيين تصنيفات القدرة على الاستمرار استتادًا إلى عوامل تحريك التصنيف الخمسة التالية:

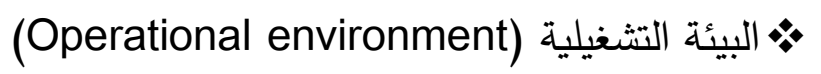
٪) ملف تعريف الثركة (Company profile)

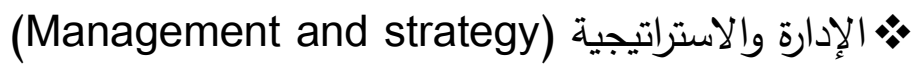

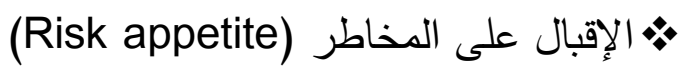
(Financial file) (الملف المالي

$$
\text { الملف المالي: جودة الأصول: }
$$

ويعتمد هذا التقييم على النسب التالية:

1- مخصص القروض المشكوك في تحصيلها الى اجمالي القروض القروض المشكوك في تحصيلها

$$
\text { نسبة التغطية }=1 \text { ×... × اجمالي القروض }
$$




\section{التصنيف الائتماني لوكالة فيتش ودوره في هنج القروض وجذب الودائع}

جدول (Y) درجة العامل الضمنية لجودة الأصول

\begin{tabular}{|c|c|c|c|c|c|}
\hline B ومادونها & $\mathrm{bb}$ & $\mathrm{Bbb}$ & $a$ & $\mathrm{Aa}$ & درجة العامل \\
\hline $1 \leqslant<$ & $1 \leqslant>$ & $7>$ & r> & $1>$ & $\mathrm{Aa}$ \\
\hline $1 K<$ & $|r\rangle$ & $0>$ & $r>$ & $\cdot, Y O>$ & $A$ \\
\hline $1 .<$ & $1 .>$ & $\varepsilon>$ & $\cdot, 0>$ & & $\mathrm{Bbb}$ \\
\hline $0<$ & $0>$ & $\cdot, \vee 0>$ & & & $\mathrm{Bb}$ \\
\hline $1<$ & $1>$ & & & & B وما دونها \\
\hline
\end{tabular}

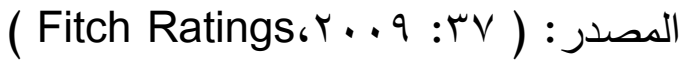

r- ( بمو إجمالي القروض (\%)

ويمكن احتساب هذه النسبة من خلال المعادلة الاتية :

السنة الحالية - السنة السابقة

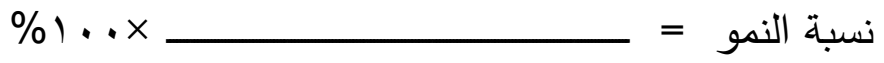

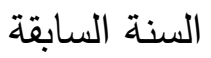

r- مخصصات القروض المعدومة الى القروض المشكوك في تحصيلها

ويمكن احتساب هذه النسبة من خلال المعادلة الآتية:

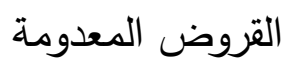

$\% 1 \ldots \times$

المشكوك في تحصيلها

ع - رسوم انخفاض قيمة القروض/متوسط إجمالي القروض 


\section{التصنيف الائتهاني لوكالة فيتش ودوره في منح القروض وبذب الودائع}

ويمكن احتساب هذه النسبة من خلال المعادلة التالية : رسوم انخفاض قيمة القروض

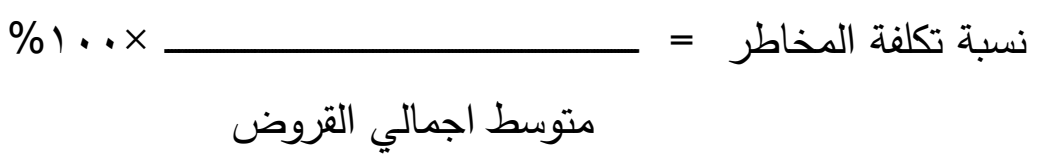

يمثل البسط الربح التثغيلي قبل اقتطاع الضريبة ،اما المقام هو الاصول المرجحة بالمخاطر المبلغ عنها (Fitch Ratings، $\mathrm{Y} \cdot 1 \wedge: \wedge 0$ ) ويمكن احتسابها من خلال المعادلة :

الربح التشغيلي

$\% 1 \ldots \times$ الارباح التشغيلية الى الاصول المرجحة بالمخاطر = الاصول المرجحة بالمخاطر

جدول (r) درجة العامل الضمنية للإيرادات والربحية

\begin{tabular}{|c|c|c|c|c|c|}
\hline B وما دونها & bb & bbb & a & aa & درجة \\
\hline$\cdot, Y O->$ & $\cdot, Y_{O}-<$ & $\cdot, 0<$ & $1,0<$ & $r, v_{0}<$ & $\mathrm{Aa}$ \\
\hline .> & $\cdot<$ & $\cdot, \mathrm{V} 0<$ & $Y<$ & $\varepsilon<$ & A \\
\hline$\cdot, Y O>$ & $\cdot, Y 0<$ & $1,0<$ & $\varepsilon, Y_{0}<$ & & $\mathrm{Bbb}$ \\
\hline $1, r o>$ & $1, Y 0<$ & $\varepsilon, \vee 0<$ & & & $\mathrm{Bb}$ \\
\hline $0>$ & $0<$ & & & & B وما دونها \\
\hline
\end{tabular}




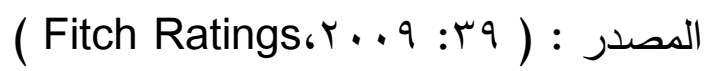

r - صافي دخل الفوائد/ الأصول المدرة للربح

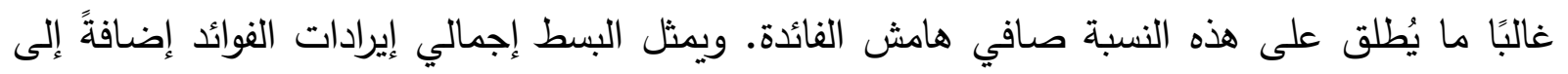
توزيعات الأرباح المستلمة مطروحا منها إجمالي نفقات الفوائد، بينما يكون المقام اجمالي الأصول

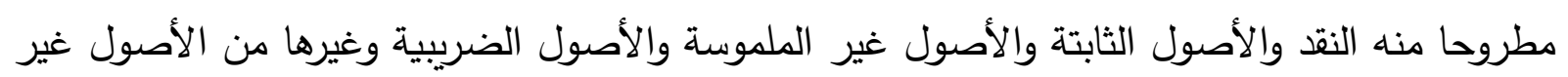

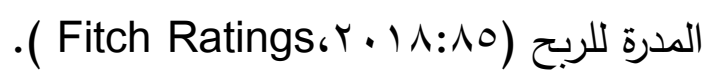
صافي دخل الفوائد

$$
\text { صافي هامش الفائدة = × × الاصول المدرة للربح }
$$

$$
\text { ب- نفقات غير الفوائد الى إجمالي الإيرادات: }
$$
غالبًا ما يطلق على هذا المقياس نسبة التكلفة أو الدخل. ويمثل البسط تكاليف الموظفين مضافًا إليه النفقات التي تعتبرها فيتش غير تثغيلية، ويتألف المقام من جميع الإيرادات التشغيلية.

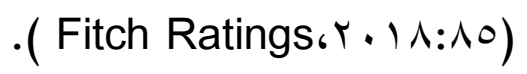
نفقات غير الفوائد

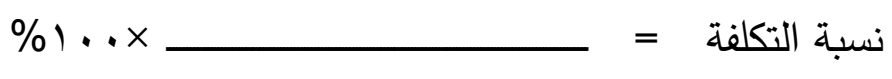

$$
\begin{aligned}
& \text { اجمالي الايرادات }
\end{aligned}
$$

ع - رسوم انخفاض قيمة القروض /الربح التشغيلي قبل انخفاض القيمة: يقيس هذا المقياس مقدار أرباح المصرف التي تستهلكها رسوم انخفاض القيمة. ويمثل البسط إجمالي رسوم انخفاض القيمة من القروض، بينما يمثل المقام الربح التشغيلي (كما هو الحال في المقياس اعلاه)

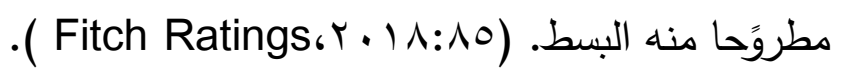




$$
\begin{aligned}
& \text { رسوم انخفاض قيمة القروض الى الربح التشغيلي قبل انخفاض القيمة = } \\
& \text { رسوم انخفاض قيمة القروض لربع } \\
& \% 1 . . x \\
& \text { الربح التشغيلي قبل انخفاض القيمة } \\
& \text { 0- الربح التشغيلي الى متوسط إجمالي الأصول: }
\end{aligned}
$$

هذا المقياس يشبه المقياس الاول للإيرادات والربحية، ولكن في صورة أولية ، ويمثل البسط الثيء نفسه، بينما المقام هو متوسط إجمالي الاصول، ولا يجرى أي تعديل بما يعكس مدى خطولئ فئي فورة نشر رأس المال

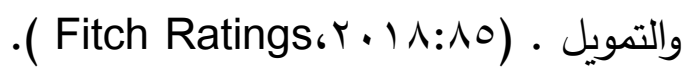

$$
\begin{aligned}
& \text { الربح التثغيلي }
\end{aligned}
$$

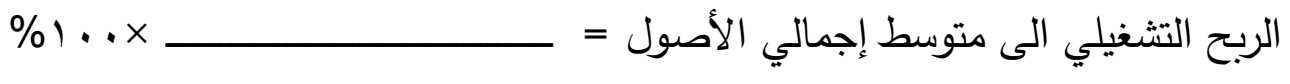

$$
\begin{aligned}
& \text { متوسط اجمالي الاصول } \\
& \text { 7- صافي الدخل الى متوسط إجمالي حقوق الملكية }
\end{aligned}
$$

يُسمى هذا المقياس عادةً العائد على حقوق الملكية. ويمكن احتساب هذه النسبة من خلال المعادلة الاتية:

$$
\begin{aligned}
& \text { صافي الدخل } \\
& \text { العائد على حقوق الملكية = } \\
& \text { متوسط اجمالي حق الملكية } \\
& \text { ثالثاً : رأس المال والرفع المالي }
\end{aligned}
$$

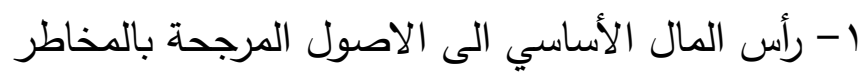

$$
\begin{aligned}
& \text { وتحتسب هذه النسبة من خلال المعادلة الاتية : }
\end{aligned}
$$




\section{التصنيف الائتباني لبوكالة فيتش ودوره في منج القروض وجغب الودائع}

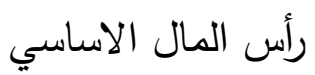

$\% 1 \cdot \times$ رأس المال الأساسي الى الاصول المرجحة بالمخاطر=

الاصول المرجحة بالمخاطر

جدول (ع) درجة العامل الضمنية لرأس المال والرفع المالي

\begin{tabular}{|c|c|c|c|c|c|}
\hline B وما دونها & bb & bbb & a & aa & الضدمنية \\
\hline $7>$ & $7<$ & $\Lambda<$ & $1 .<$ & $17<$ & aa \\
\hline$v>$ & $V<$ & $9<$ & $1 \leqslant<$ & $11<$ & a \\
\hline$\wedge>$ & $\Lambda<$ & $1 T<$ & $19<$ & & $\mathrm{bbb}$ \\
\hline$|r\rangle$ & $\mid r<$ & $r \cdot<$ & & & $\mathrm{bb}$ \\
\hline$r r>$ & $Y Y<$ & & & & B وما دونها \\
\hline
\end{tabular}

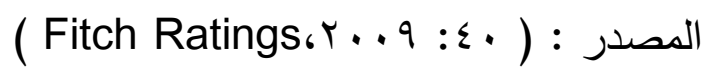

r- نسبة رأس المال التنظيمي لحقوق الملكية العادية من المستوى الأول ويمثل البسط رأس مال حقوق الملكية العادية من المستوى الأول( (CET) والمقام يمثل الأصول المرجحة

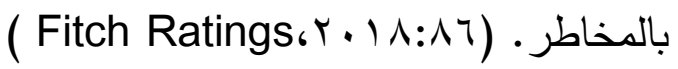

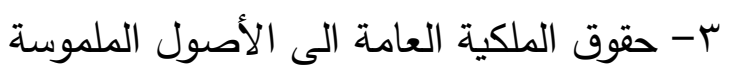
ويمكن احتساب هذه النسبة من خلال المعادلة الاتية: 


\section{التصنيف الائتباذي لوكالة فيتش ودوره في منج القروض وجذب الودالع}

حقوق الملكية العامة

$\% 1 \cdots \times$ حقوق الملكية العامة الى الأصول الملموسة =

الأصول الملموسة

ع- القروض المشكوك في تحصيلها مطروحا منها مخصصات القروض المعدومة الى رأس المال

رابعا : التمويل والسيولة:

1- القروض الى ودائع العملاء

يستثني البسط والمقام القروض والودائع لدى المصارف الأخرى واتفاقيات إعادة الثراء، ولكن يُدرج جميع

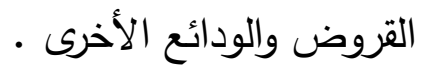

جدول (0) درجة العامل الضمنية للتمويل والسيولة

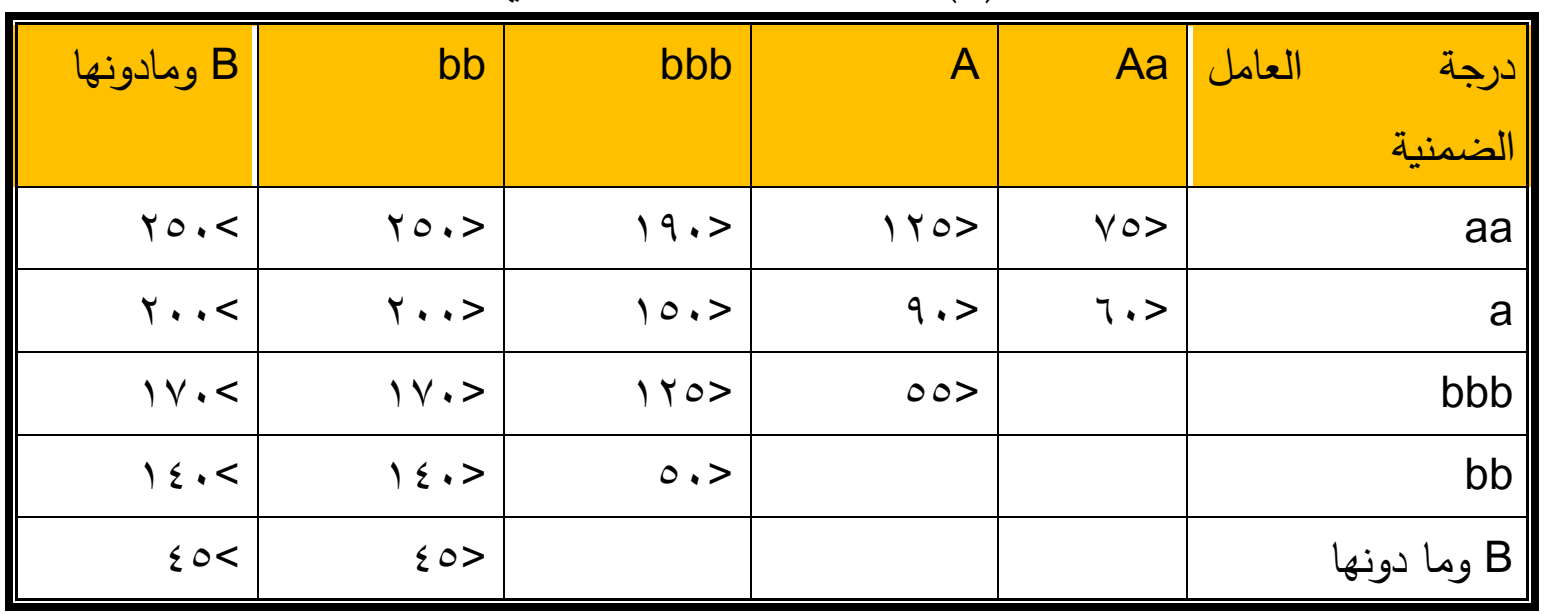

(Fitch Ratings،r... 9 (المصدر : )

r- نسبة تغطية السيولة:

ويمكن احتسابها وفق المعادلة الاتية : 


\section{التصنيف الائتماني لوكالة فيتش ودوره في منح القروض وجذب الودالع}

أصول عالية السيولة

$\% 1 \ldots \times$ نسبة تغطية السيولة =

التدفقات التقديرية الخارجة في فترة مدتها • ب يوما r- ودائع العملاء الى إجمالي التمويل

ودائع العملاء

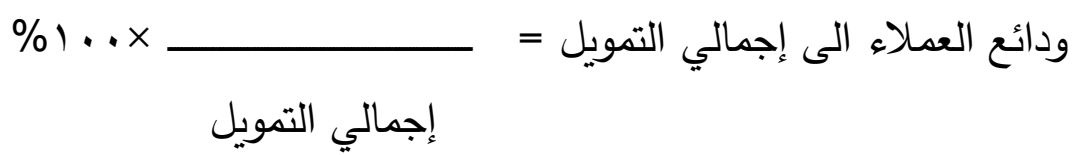
المصرف الاهلي المتحد: يرجع تاريخ هذا المصرف إلى عام إو 19 عندما أنشئ البنك الإمبراطوري الإيراني على يد مجموعة من

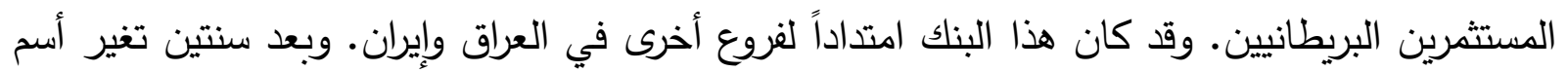
البنك إلى البنك البريطاني في إيران والثرق الأوسط. وفي الخمسينيات من القرن العشرين ونتيجة لتوتر

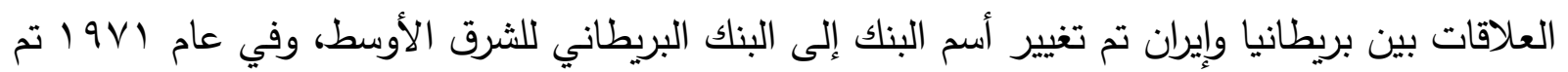
تأميم البنك وتحويله إلى بنك الكويت والثرق الأوسط بعد سن قانون يمنع مزاولة البنوك الأجنبية للأنشطة

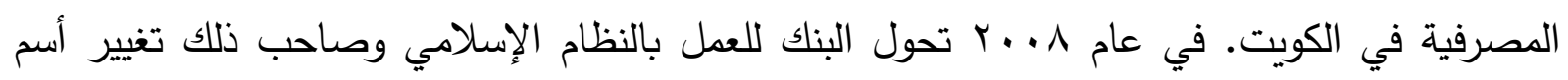
البنك ليصبح البنك الأهلي المتحد، وقد أتى قرار تحويل تعاملات البنك لتتوافق مع المبادئ الإسلامية

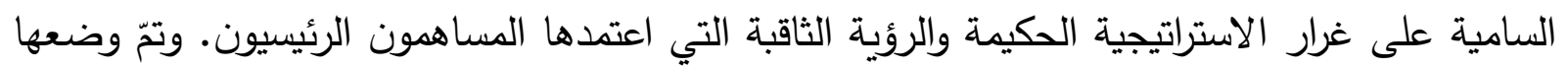
موضع التنفيذ من قبل الإدارة التنفيذية للبنك تحت إثراف مجلس إدارتها. وهكذا، استطاع " البنك الأهلي

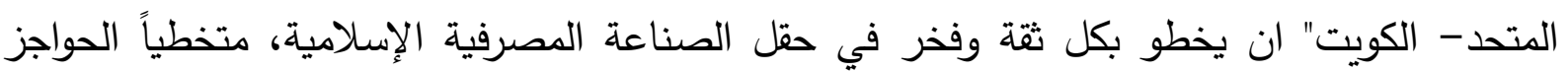
والصعوبات، متصدراً المصارف الإسلامية ورائداً في زرع الثقة المتبادلة وحصاد النجاحات المشتركة، كما لثالئه

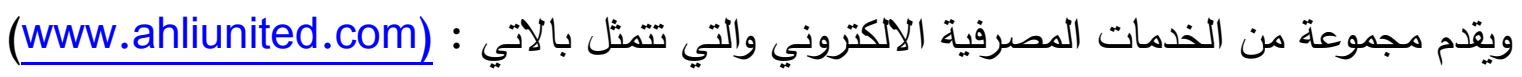

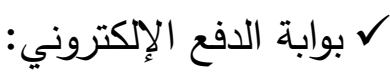


ل حدمة الرسائل النصية القصيرة $\checkmark$ $\checkmark$ $\checkmark$

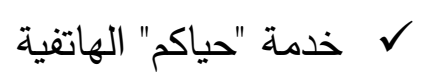
$\checkmark$ E-School خدمة

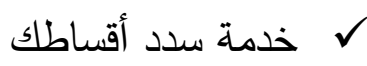

تحليل معايير التصنيف الائتماني للمتغير المستقل: نبدأ اولا بتحليل معايير التصنيف للمتغيرات المستقلة وهي (جودة الاصول، التمويل والسيولة، الايرادات و

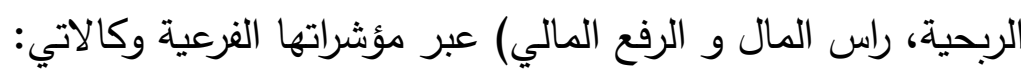

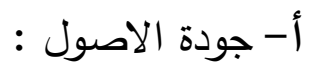

الجدول (0) يوضح احتساب جودة الاصول للمصرف الاهلي المتحد، وعبر مؤشراته الاربعة وهي

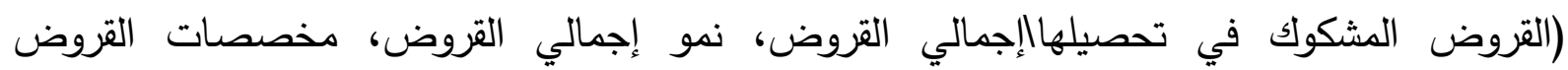
المعدومةالقروض المشكوك في تحصيلها، رسوم انخفاض قيمة القروضامتوسط إجمالي القروض)، و كالاتي: جدول (10) احتساب جودة الاصول للمصرف الاهلي المتحد

\begin{tabular}{|c|c|c|c|c|c|}
\hline \multirow[b]{2}{*}{ الحسابي } & \multicolumn{4}{|c|}{ المؤشرات } & \multirow[b]{2}{*}{ السنوات } \\
\hline & القروض قروم انخفاض & المعدصدات & نمو إجمالي & تحصيلها في إجمالي المشكوك & \\
\hline
\end{tabular}




\section{التصنيف الائتماني لمكالة فيتش ودوره في هنج القروض وجثب الودائع}

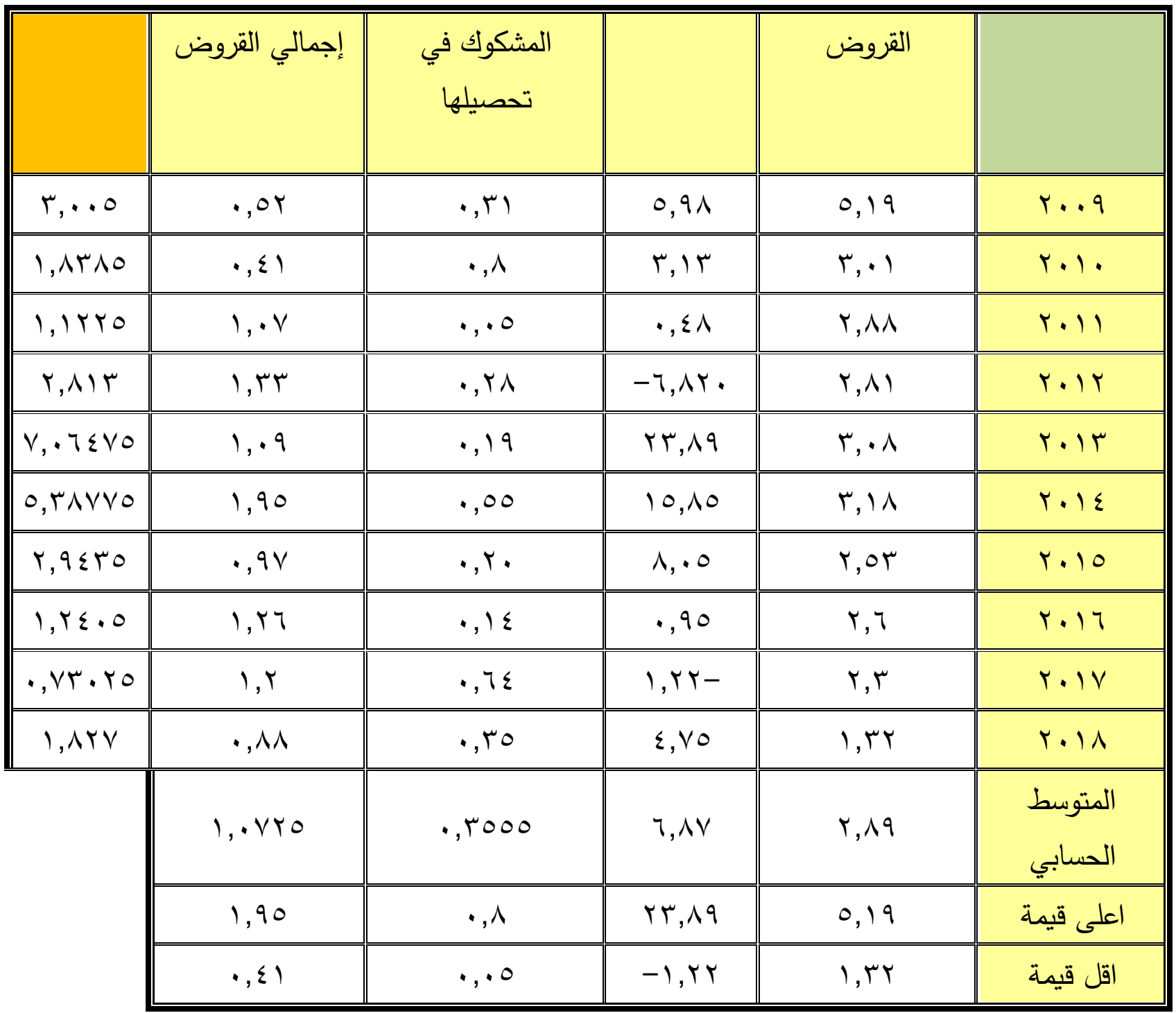

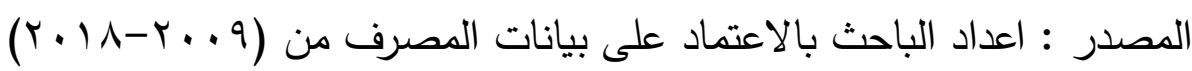

من الجدول (10) يتضح ان هنالك انخفاض في نسب مؤشر القروض المشكوك في تحصيلها الى

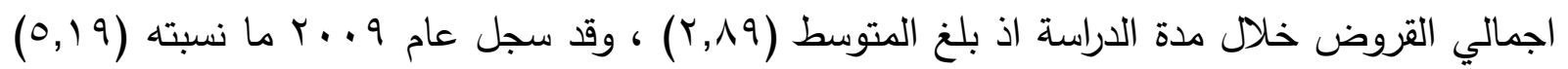




\section{التصنيف الائتصاني لوكالة فيتش ودوره في منح القروض وجذب الودائع}

و هي اعلى نسبة محققة على مدى سنوات الدراسة للمصرف الاهلي المتحد ، وسجلت انخفاضاً متكرراً

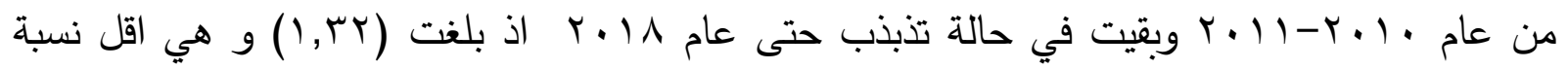
محققة طيلة مدة الدراسة للمصرف الاهلي المتحد ، وهذا يدل على ان المصرف حسن من قدرته في تقليص الديون المشكوك في تحصيلها خلال مدة الدراسة ، و هو ما اثر بثكل ايجابيا في معيار القدرة

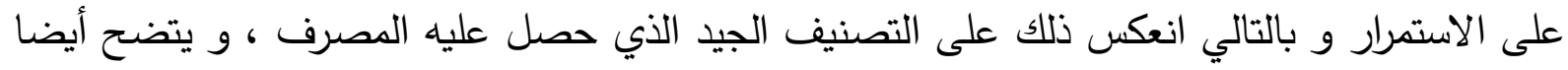

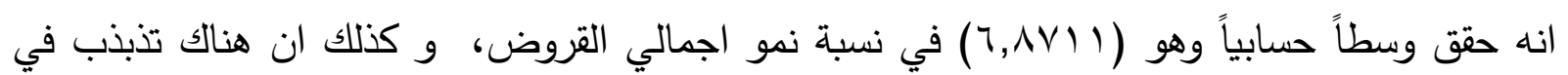

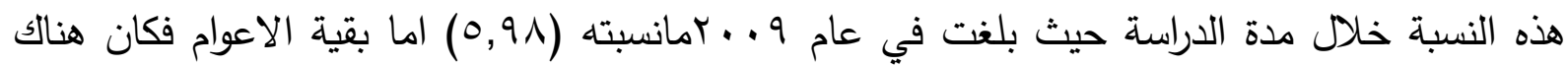

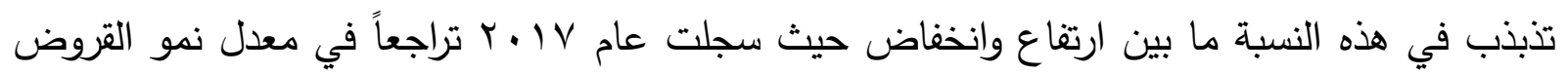

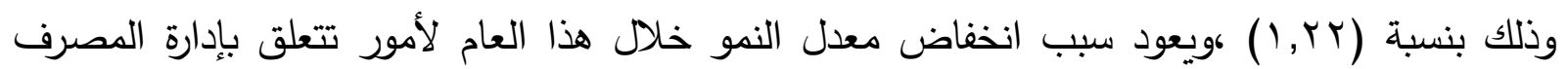
المانح للائتمان والذي يقوم بدوره بتحليل نوع القرض وتثييم الزبائن المحتمل تعرضهم للتعثر المالي وتقييم

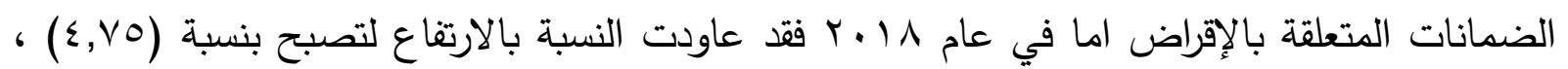

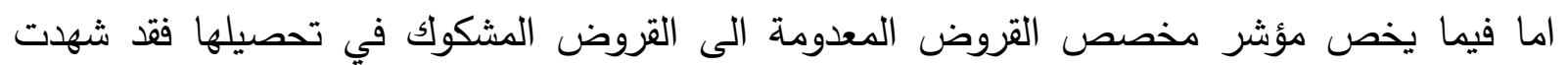

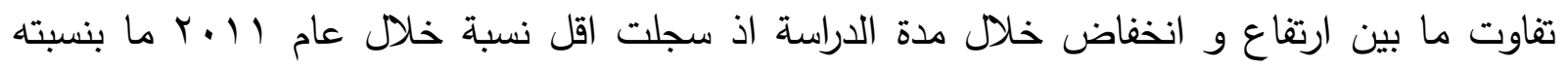

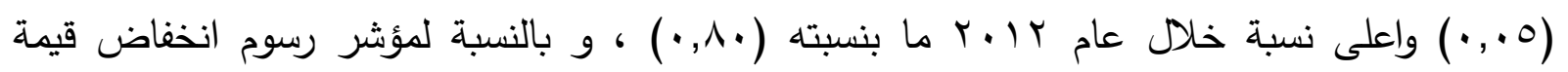

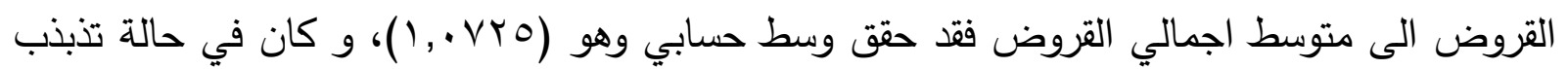

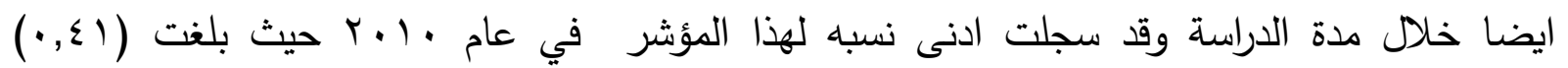

$$
\begin{aligned}
& \text { وشهدت اعلى نسبة في عام ع ا ـr بنسبة (90, 1 ). } \\
& \text { ب- التمويل والسيولة: }
\end{aligned}
$$

الجدول (T (1) يوضح احتساب التمويل و السيولة للمصرف الاهلي المتحد، و عبر مؤشراته الثلاثة و

هي (القروضا ودائع العملاء، نسبة تغطية السيولة، ودائع العملاءاإجمالي التمويل) ، و كالاتي : 


\section{التصنيف الائتماني لوكالة فيتش ودوره في منج القروض وجذب الودالع}

الجدول (7 (1) احتساب التمويل والسيولة للمصرف الاهلي المتحد

\begin{tabular}{|c|c|c|c|c|}
\hline \multirow{2}{*}{ الحستوسط } & \multicolumn{3}{|c|}{ المؤشرات } & \multirow[b]{2}{*}{ السنوات } \\
\hline & الجمالي التمويل العملاء & نسبة تغطية & القروض| ودائع & \\
\hline$\vee 9, \wedge 0$ & $\wedge r, q \wedge$ & $\vee \wedge, \cdot r$ & VA,Or & $r \ldots q$ \\
\hline$q \leq, V \leq$ & $11 \leqslant, 07$ & Vi, so & $V \varepsilon, q r$ & $r \cdot 1$. \\
\hline $1 . r, 1$. & $|v \cdot, q|$ & $T \Lambda, \varepsilon r$ & $79,9 \vee$ & $r .11$ \\
\hline$q \pi, v \leq$ & $10 ., 9 r$ & 00,11 & $V O, r$ & $r . I T$ \\
\hline $9 \varepsilon, \cdot 1$ & $1 \leq 0,7 V$ & 09,91 & $V 7,70$ & $r .1 T$ \\
\hline $9 \cdot, 11$ & 1ז,9, & $07, T_{1}$ & $V Y, Y \leq$ & $r \cdot 1 \leq$ \\
\hline $1 \pi \varepsilon, r$. & $r V \cdot, \Lambda$ & $00, \cdot 1$ & $V T, V Y$ & $r .10$ \\
\hline NT,Yr & $7 \cdot, 1$ & $1 \cdot 1, \wedge 7$ & $\Lambda \varepsilon, V Y$ & $r .17$ \\
\hline $1.9, \varepsilon$. & $1 \leqslant r, 10$ & $1 \cdots, V V$ & $10, r_{9}$ & r. IV \\
\hline \multirow[t]{4}{*}{$1 \cdot 0,0 \leqslant$} & $|r r, 0|$ & $1 \cdots, r q$ & $\Lambda r, v)$ & $r \cdot 11$ \\
\hline & $1 \leq \cdot, \vee v 7$ & vo, l. & $\vee \wedge, r$. & الحسابي \\
\hline & $r V \cdot, \Lambda$ & $1 \cdot 1, \wedge 7$ & $10, Y_{9}$ & اعلى قيمة \\
\hline & $7 ., 1$ & $00, \cdot 1$ & $79,9 \vee$ & اقل قيمة \\
\hline
\end{tabular}

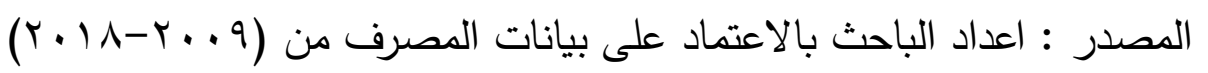




\section{التصنيف الائتمباني لبوكالة فيتش ودوره في منح القروض وجذب الودائع}

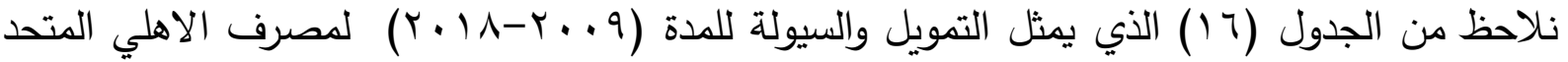

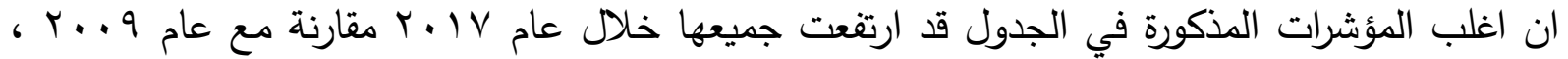
وإن ارتفاع نسبة تغطية السيولة لدى المصرف يعطيه قدرة عالية للوفاء بالتزاماته تجاه المودعين في حال حدوث سحوبات كبيرة ومفاجئة، وهذا يدعم حالة الاستقرار المالي للمصرف ،حيث ارتفعت النسبة في عام

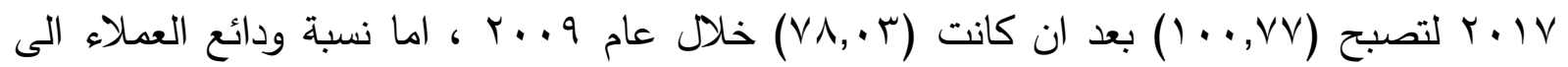

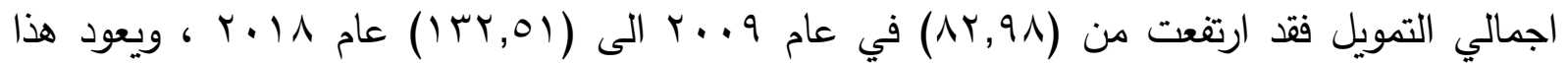
الارتفاع الى التحسن النسبي للوضع الاقتصادي خلال عام VI. V والذي انعكس على ارتفاع نسبة

$$
\text { تالايداعات لإى المصرف. }
$$

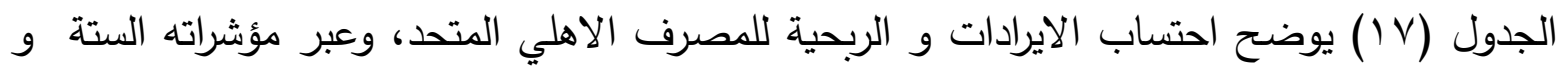

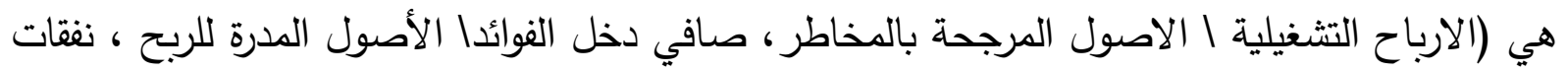
غير الفوائداإجمالي الإيرادات ، رسوم انخفاض قيمة القروض الربح التشغيلي قبل انخفاض القيمة ، الربح ، التحات ، التشغيليامتوسط إجمالي الأصول ، صافي الدخلامتوسط إجمالي حقوق الملكية ) ، و كالاتي :

\begin{tabular}{|c|c|c|c|c|c|c|c|}
\hline \multirow[b]{2}{*}{ المتوسط } & \multicolumn{6}{|c|}{ المؤشرات } & \multirow[b]{2}{*}{ السنوات } \\
\hline & الإخمالي حقوق المتوسط & التشغيليامتو الربح & قالربمة التروض التخفاض التخغيلي & الفقائداا غيرال & طالفائل المدامتوس دخل & الالارباح & \\
\hline
\end{tabular}
جدول (V V) احتساب الايرادات و الربحية لمصرف الاهلي المتحد 


\section{التصنيف الائتباني لبوكالة فيتش ودوره في منج القروض وجغب الودائع}

\begin{tabular}{|c|c|c|c|c|c|c|c|}
\hline r & ו & $\cdot, \leqslant Y$ & 0,11 & $\cdot, Y_{1}$ & $r, 70$ & $\cdot, 77$ & $r \ldots q$ \\
\hline 1,00 & •, & $\cdot, 9 \vee \varepsilon$ & $r, q 9 r$ & מז, • & r,orq & $1, \leqslant \leq 0$ & r. \\
\hline $1, \varepsilon$. & $\cdot, 910$ & $1, \ldots 1$ & $r, 100$ & $\cdot, Y \varepsilon$ & $r, 01 \varepsilon$ & 1,7 & $r .11$ \\
\hline $1, \varepsilon$. & q & $1, \leq \varepsilon \leq$ & ד & $\cdot, Y_{1}$ & $r, \wedge \leq \wedge$ & $r, r q \leq$ & $r \cdot 1 r$ \\
\hline سז, & $\cdot, 1 \leq \varepsilon$ & $1, \varepsilon \wedge$ & $\cdot, 979$ & $\cdot, r$ & $r, \tau, r$ & $r, 07 \wedge$ & r r \\
\hline $1, \cdot 9$ & $\cdot, 1 Y \varepsilon$ & qז, & $\cdot, r \leq \leq$ & $\cdot, Y_{1}$ & o & $r, r \circ V$ & $r .1 \varepsilon$ \\
\hline$\cdot, 99$ & $\cdot, 1$ & $1, r \leqslant r$ & $\cdot, 1 \leqslant r$ & $\cdot, r$ & r,orr & $1, \vee 1 \leq$ & $r .10$ \\
\hline r. & $\cdot, \wedge)$ &., 991 & ד • ז, • & $\cdot, r$ & $r, \leq 01$ & $1, \leqslant \varepsilon$ & $r .17$ \\
\hline 1,0 &., .97 & $1, r \cdot 1$ & •, & $\cdot, r Y$ & $r, q \cdot \wedge$ & 1,099 & $r .1 \mathrm{~V}$ \\
\hline \multirow[t]{4}{*}{ rו } & $\cdot, 1 \cdot 0$ & r & $\cdot, 191$ & $\cdot, r$ & $r, \tau \leqslant V$ & ז. & $r \cdot \mid \Lambda$ \\
\hline &., 79 & 1,10 & 1,00 & $\cdot, Y_{1}$ & $r, 7$. & $1, V Y$ & المتوسط \\
\hline & ו & $1, \leqslant \wedge$ & 0,11 & $\cdot, r \leq$ & $r, q 1$ & $Y, O V$ & قيمة \\
\hline & $\cdot, 1$ & $\cdot, \varepsilon r$ & $\cdot, 1 \leq$ & $\cdot, r$. & $r, r$ &., 77 & اقل قيمة \\
\hline
\end{tabular}

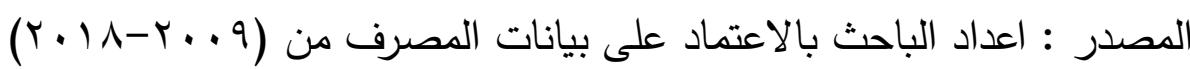

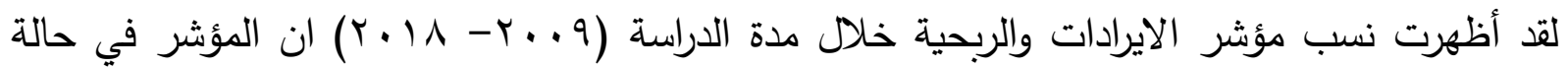

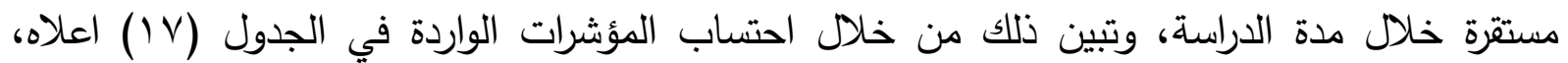

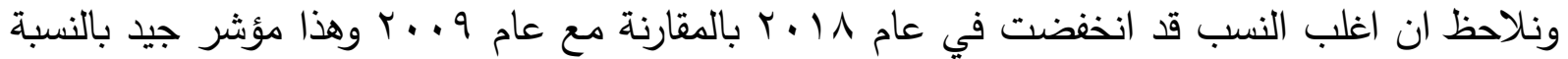
للمصرف والذي انعكس بثكل ايجابي بالنسبة لمعيار القدرة على الاستمرار، وعند تحليل نسبة الارباح 
التشغيلية الى الاصول المرجحة بالمخاطر نلاحظ ان اعلى نسبة قد سجلت في عام با •r وذلك ما

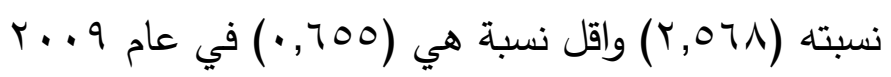
وعند العودة الى الجدول نفسه نلاحظ ان نسبة صافي دخل الفوائد الى الاصول المدرة للربح قد سجلت ما

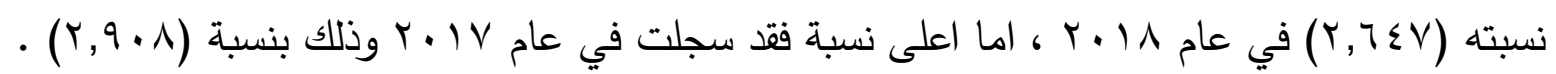
اما مؤشر نسبة نفقات غير الفوائد الى اجمالي الايرادات فنلاحظ ان هذه النسبة في حالة تحسن خلال

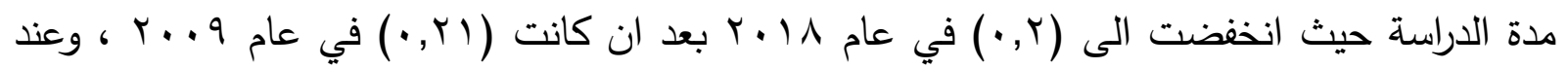
العودة الى الجدول نلاحظ ايضا ان مؤشر نسبة رسوم انخفاض قيمة القروض الى الربح التشغيلي قبل

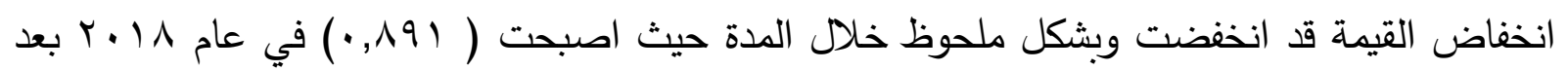

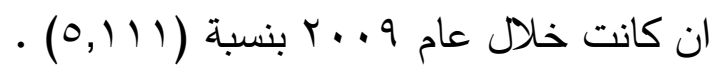

اما بالنسبة لمؤشر الربح التشغيلي الى متوسط اجمالي الاصول فقد كان في حالة تذبذب خلال مدة

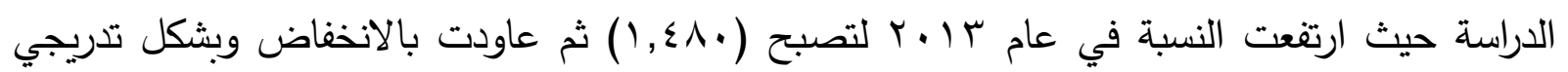

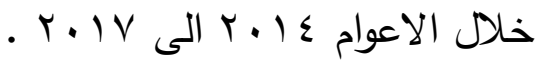
كما تثير النتائج ايضا الى ان مؤشر نسبة صافي الدخل الى متوسط اجمالي حقوق الملكية هو في حالة

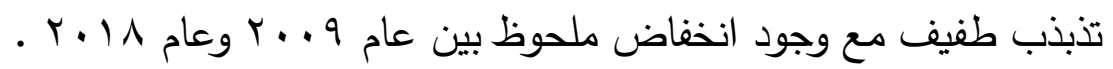

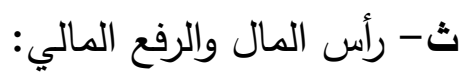
الجدول (1/) يوضح احتساب راس المال والرفع المالي للمصرف الاهلي المتحد، وعبر مؤشراته الاربعة وهي (رأس المال الأساسي \الاصول المرجحة بالمخاطر، نسبة رأس المال التنظيمي لحقوق الملكية

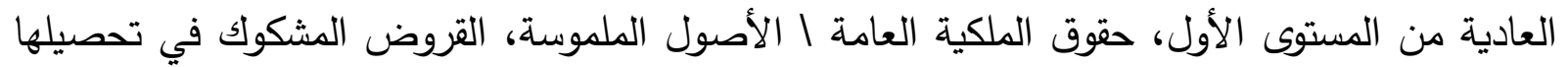

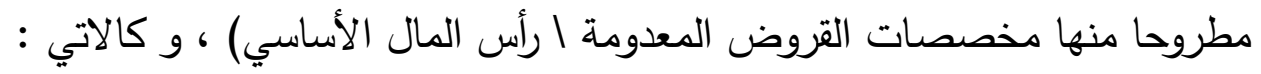




\section{التصنيف الائتصاني لوكالة فيتش ودوره في منح القروض وجذب الودائع}

جدول (1 (1) احتساب راس المال و الرفع المالي للمصرف الاهلي المتحد

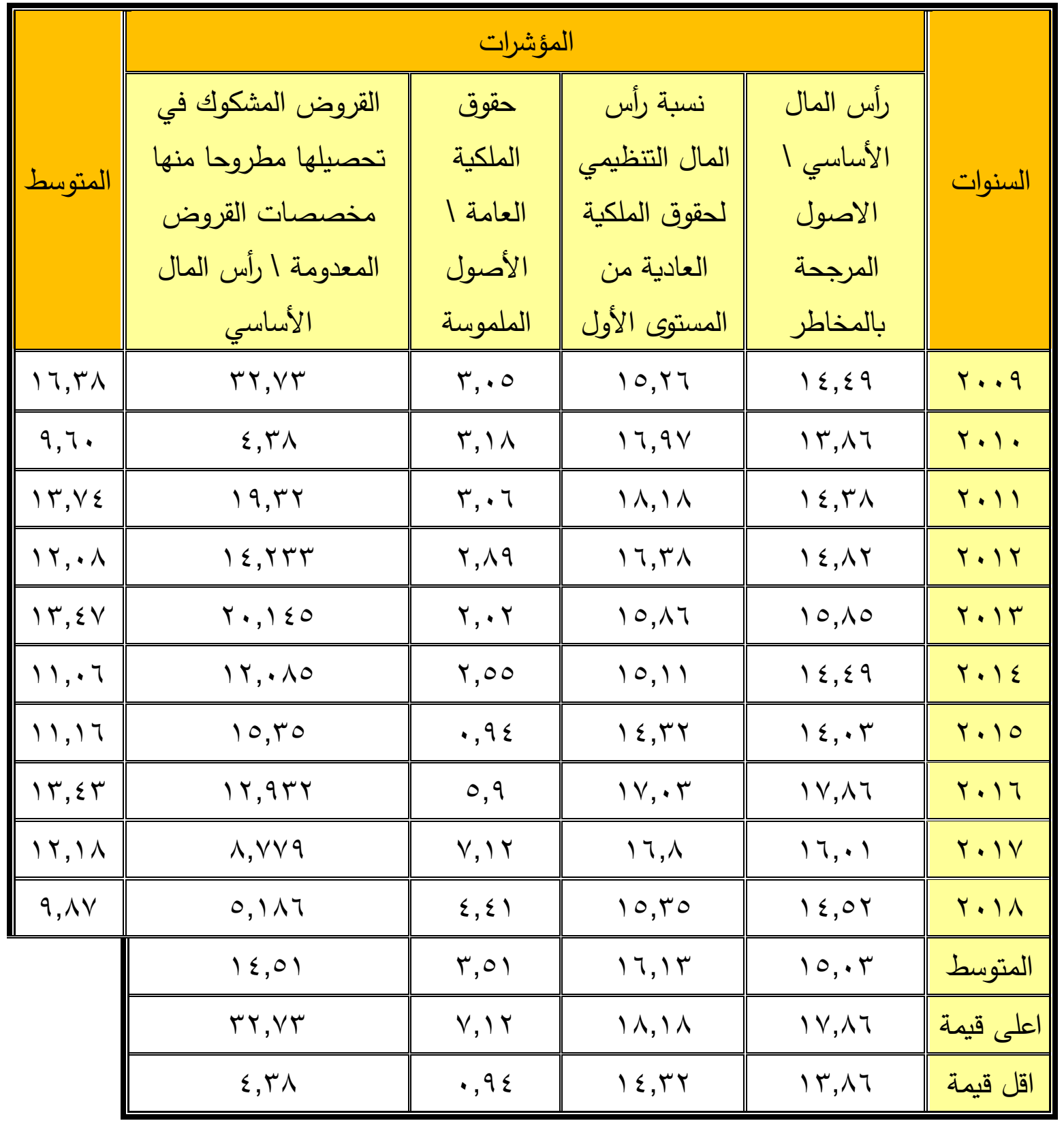




\section{التصنيف الائتصاني لوكالة فيتش ودوره في منح القروض وجذب الودائع}

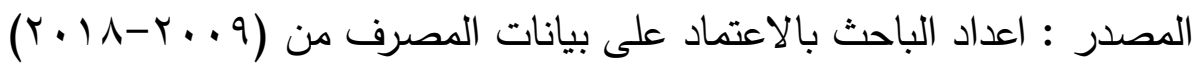

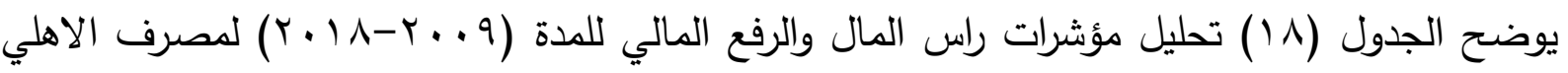
المتحد ، والنظرة الاولية تعطي دلالة واضحة على التطور الحاصل في الملاءة المالية من اجل تحسين بيئة العمل المصرفي من خلال ارتفاع نسب رأس المال المصرفي ونموها بشكل ملحوظ ، ويمكن الاستدلال على ذلك ، عند النظر الى قيم متوسط نسب مؤشر رأس المال نلاحظ ان اعلى قيمة للمتوسط

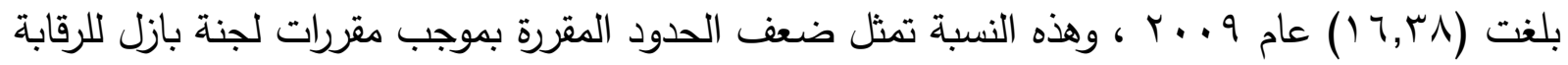
المصرفية ، و ادنى قيمة للمتوسط بلغت ( ـ, 9, ) وهي اعلى من الحد المقرر من قبل لجنة بازل ، اما

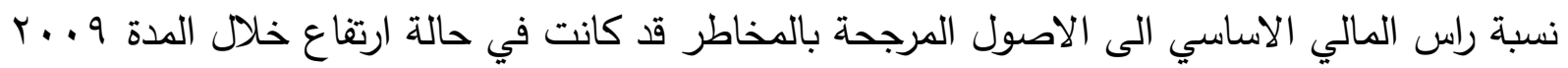

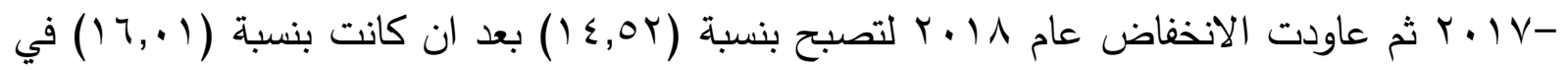

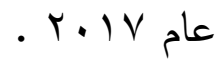

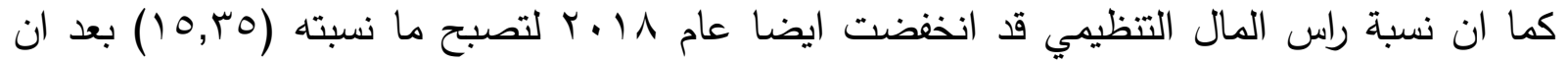

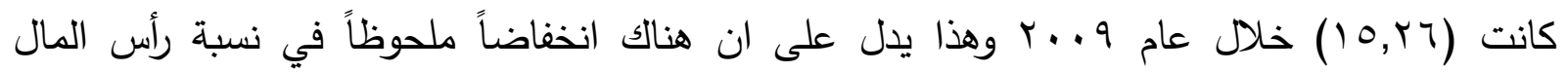

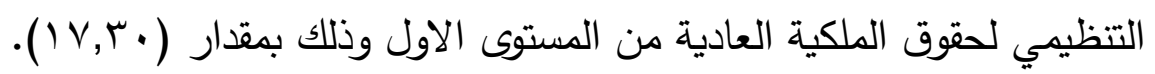
اما فيما يخص نسبة حقوق الملكية العامة الى الاصول الملموسة فقد شهدت حالة من التذبذب خلال مدة الته

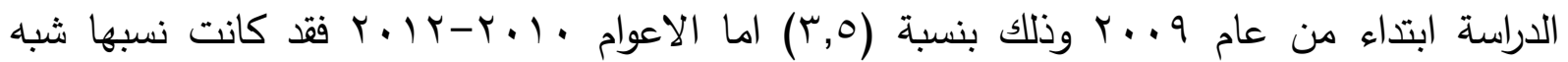

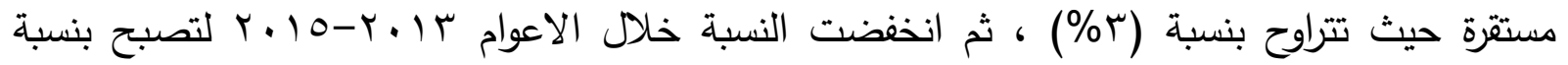

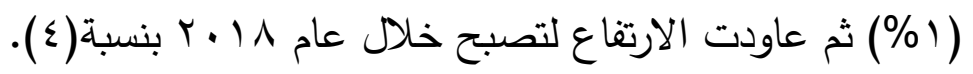
كما يبين الجدول (1) ان نسبة القروض المشكوك في تحصيلها مطروحا منها مخصصات القروض المعدومة الى راس المال الاساسي فقد شهدت حالة من التذبذب خلال مدة الدراسة ما بين ارتفاع

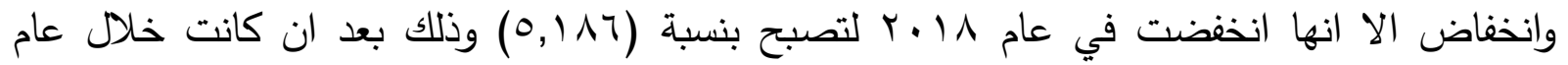




\section{التصنيف الائتصاني لوكالة فيتش ودوره في منح القروض وجذب الودائع}

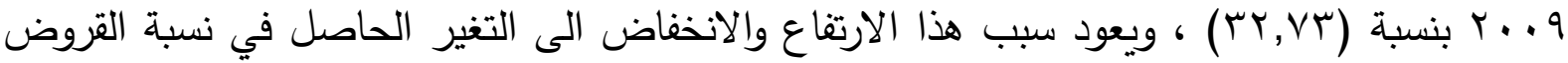
المتعثرة خلال مدة الدراسة ـ الماسل مما تقدم يتضح ان نسب المؤشرات في حالة انخفاض خلال مدة الدراسة وهذا يدل على ان المصرف في

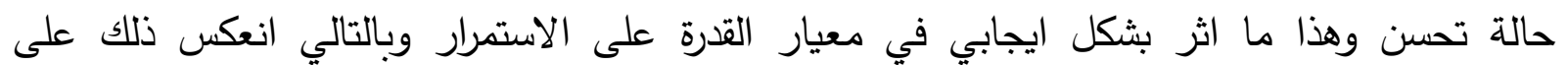

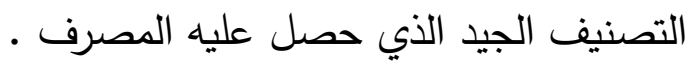
تحليل علاقات الارتباط بين متغيرات الدراسة: تخصص هذه الفقرة باختبار فرضيات الدراسة و الخاصة بالارتباط ، اذ يتم اولا حساب قيمة الارتباط (R) وبعدها اختبار معنوية علاقة الارتباط بواسطة اختبار المعنوية (P) ، و قام الباحث باحتساب معامل لإل ارتباط بيرسون للمتغيرات الكمية ، و ذلك عن طريق اخذ الاوساط الحسابية للمتغيرات المستقلة و كذلك المتغيرات التابعة ، وبحسب الاتي: التبون أ أنتبار فرضيات الارتباط للمصرف الاهلي المتحد أ-الفرضية الرئيسة الاولى : و التي تتص على : التصنيات

" توجد علاقة ارتباط معنوي لجودة الاصول على القروض على مستوى مصرف الاهلي المتحد" لونى من خلال النتائج الواردة ضمن الجدول (r؟) يتضح عدم وجود علاقة ارتباط معنوية بين جودة الاصول

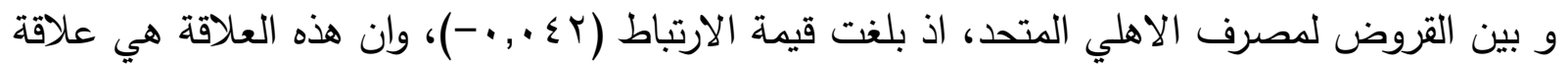

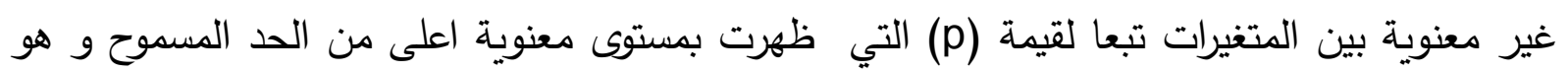

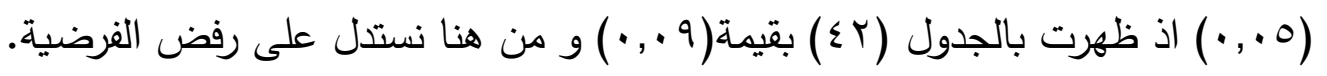
ب- الفرضية الرئيسة الثانية : و التي تتص على :

" توجد علاقة ارتباط معنوي للتمويل والسيولة على القروض على مستوى مصرف الاهلي المتحد".

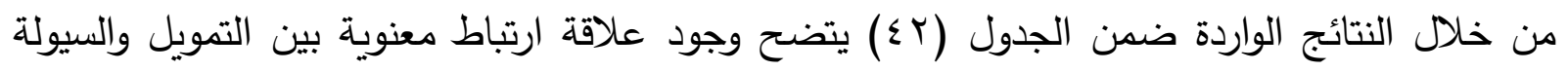
وبين القروض لمصرف الاهلي المتحد، اذ بلغت قيمته الارتباط (آ • ع, •)، وان هذه العلاقة هي علاقة 


\section{التصنيف الائتصاني لوكالة فيتش ودوره في منح القروض وجذب الودائع}

معنوية بين المتغيرات تبعا لقيمة (p) التي ظهرت بمستوى معنوية اقل من الحد المسموح و هو (0., •)

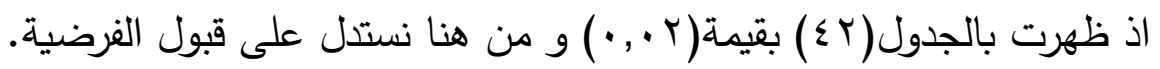

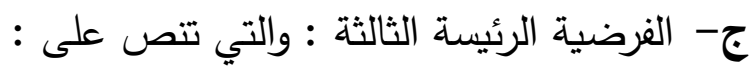

" توجد علاقة ارتباط معنوي للإيرادات والربحية على القروض على لعى مستوى مصرف الاهلي المتحد". من خلال النتائج الواردة ضمن الجدول (rع) يتضح وجود علاقة ارتباط معنوية بين الايرادات و الربحية

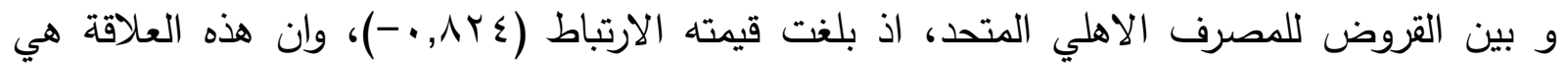
علاقة معنوية بين المتغيرات تبعا لقيمة (p) التي ظهرت بمستوى معنوية اقل من الحد المسموح و هو

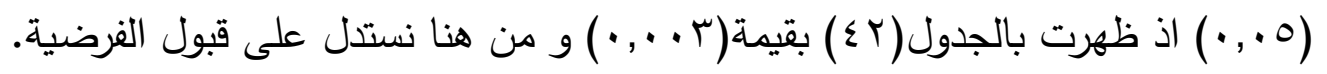
د-الفرضية الرئيسة الرابعة : و التي تتص على : لتص "توجد علاقة ارتباط معنوي لراس المال و الرفع المالي على القروض على على مستوى مصرف الاهلي

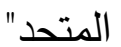

من خلال النتائج الواردة ضمن الجدول (r؟) يتضح عدم وجود علاقة ارتباط معنوية بين راس المال و الرفع المالي وبين القروض لمصرف الاهلي المتحد، اذ بلغت قيمته الارتباط (ץ+..•)، وان هذه العلاقة

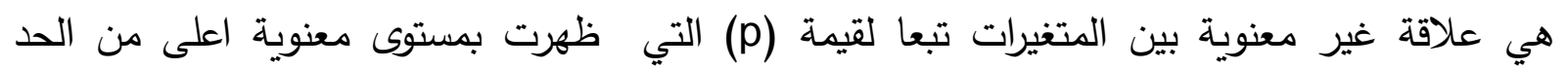

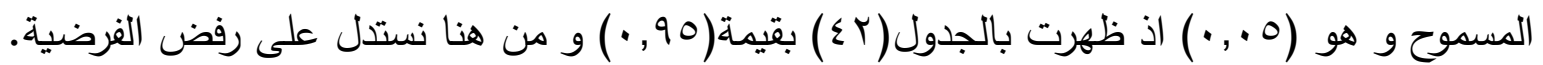
هـ - الفرضية الرئيسة الخامسة : و التي تتص على :

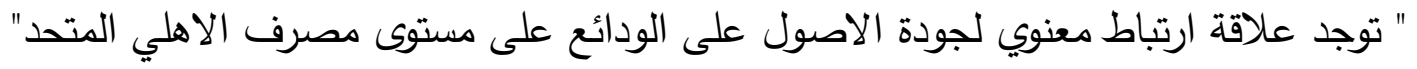
من خلال النتائج الواردة ضمن الجدول (r؟) يتضح عدم وجود علاقة ارتباط معنوية بين جودة الاصول وبين الودائع لمصرف الاهلي المتحد ، اذ بلغت قيمته الارتباط (0., •)، وان هذه العلاقة هي علاقة غير معنوية بين المتغيرات تبعا لقيمة (p) التي ظهرت بمستوى معنوية اعلى من الحد المسموح و هو (0., • •)

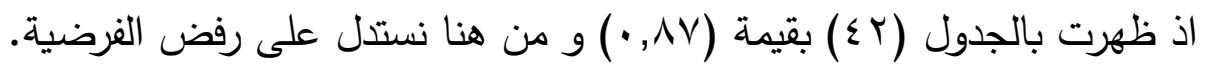


و - الفرضية الرئيسة السادسة : والتي تتص على : " توجد علاقة ارتباط معنوي للتمويل والسيولة على الودائع على مستوى مصرف الاهلى الهلي المتحد". من خلال النتائج الواردة ضمن الجدول (r\&) يتضح وجود علاقة ارتباط معنوية بين التمويل و السيولة و

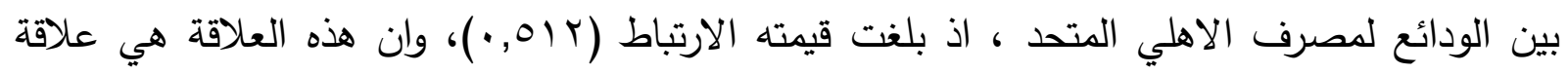
معنوية بين المتغيرات تبعا لقيمة (p) التي ظهرت بمستوى معنوية اقل من الحد المسموح و هو (0., • •)

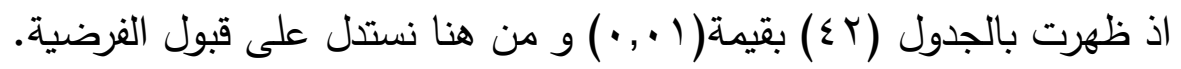

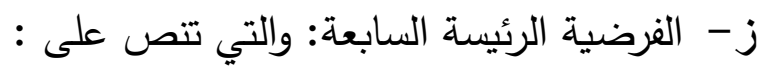

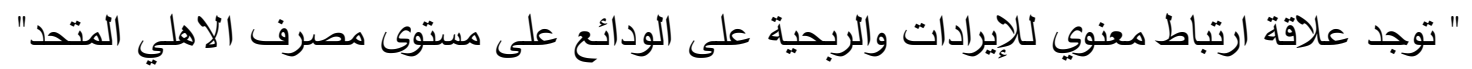

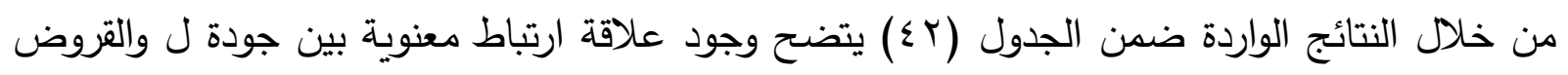
لمصرف الاهلي المتحد، اذ بلغت قيمته الارتباط (مV0, •--)، وان هذه العلاقة هي علاقة معنوية بين المتغيرات تبعا لقيمة (p) التي ظهرت بمستوى معنوية اقل من الحد المسموح و هو (0., •) اذ ظهرت

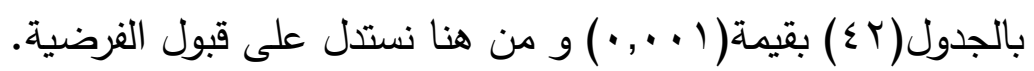
ح- الفرضية الرئيسة الثامنة : والتي تنص على بلى " توجد علاقة ارتباط معنوي لراس المال والرفع المالي على الودائع على مستوى مصرف الاهلي المتحدي"

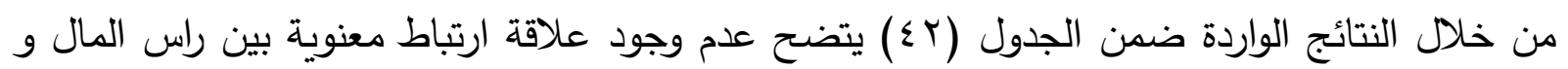

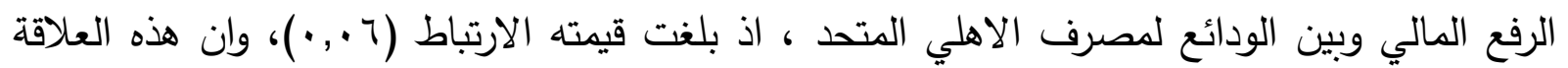

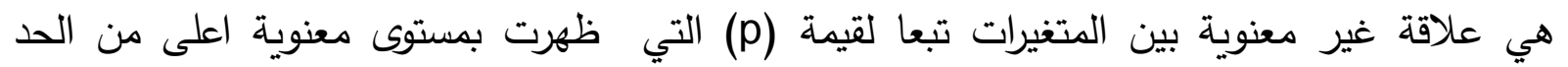

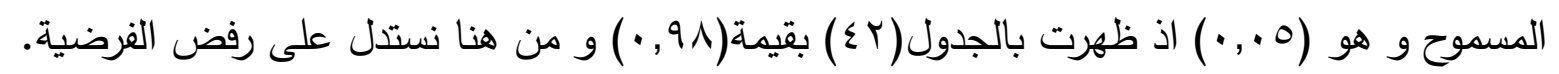




\section{التصنيف الائتماني لوكالة فيتش ودوره في منح القروض وجذب الودائع}

جدول (rع) اختبار فرضيات الارتباط لمصرف الاهلي المتحد

\begin{tabular}{|c|c|c|c|c|c|}
\hline النتيجة & المعنوية & $P$ & $\mathrm{R}$ & المتغيرات & ت \\
\hline مرفوض & غير معنوي & $\cdot, \cdot 9$ & $-\cdot, \cdot \leq r$ & $y_{11} \longleftrightarrow x_{11}$ & 1 \\
\hline مقبول & معنوي & $\cdot, \cdot r$ & $*,, \varepsilon\rceil$, & $\longrightarrow X_{1 r}$ & r \\
\hline مقبول & معنوي & $\cdot, \cdot r$ & $* *-, \wedge r \leq$ & $\longrightarrow X_{1 r}$ & r \\
\hline مرفوض & غير معنوي & $\cdot, 90$ & $\cdot, \cdot r$ & $\rightarrow X_{1 \varepsilon}$ & $\varepsilon$ \\
\hline مرفوض & غير معنوي & $\cdot, \wedge \vee$ & $\cdot, .0$ & $y_{i r} \leftarrow$ & 0 \\
\hline مقبول & معنوي & $\cdot, \cdot 1$ & $* *, 01 r$ & $y_{1,} \leftarrow$ & 7 \\
\hline مقبول & معنوي & $\cdot, \cdots 1$ & $* *-, \wedge \vee 0$ & $y_{1,} \leftarrow$ & v \\
\hline رفض ر & غير معنوي & $\cdot, 91$ & $\cdot, \cdots 7$ & $y_{i r} \leftarrow$ & $\wedge$ \\
\hline
\end{tabular}

Spss V.r المصدر : اعداد الباحث بالاعتماد نتائج برنامج

$$
\begin{aligned}
& \text { (** تعني الارتباط معنوي عند مستوى دلالة (a=0 •, • (•) }
\end{aligned}
$$

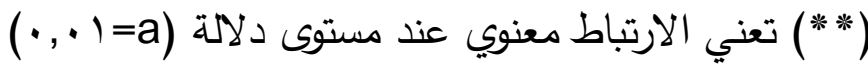

$$
\begin{aligned}
& \text { 1- اختبار فرضيات التأثير لمصرف الاهلي المتحد: }
\end{aligned}
$$

أ- الفرضية الرئيسة الاولى : والتي تتص على "يوجد تأثير معنوي لجودة الاصول على القروض على مستوى مصرف الاهلي المتحد " ان قيمة (f) المحسوبة والتي تقيس معنوية نموذج الانحدار البسيط كانت اقل من الجدولية وهي (79, §)

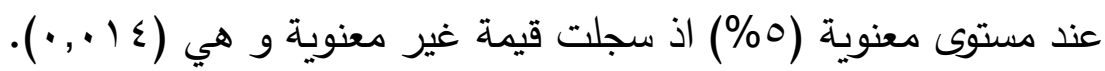

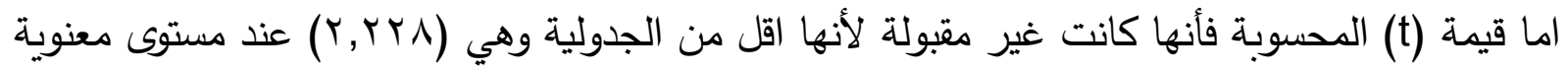

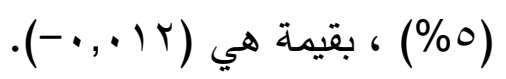




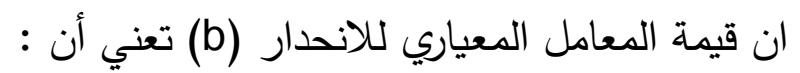

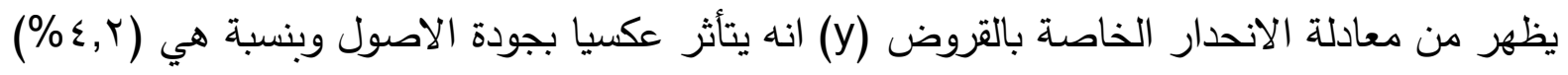

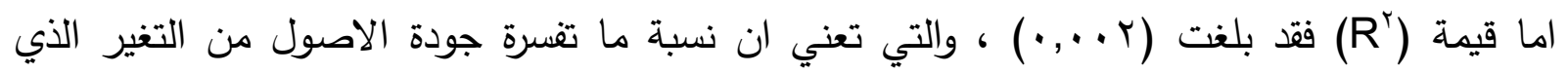
يحصل بالقروض هو (r, • \%) ، و من خلال النتائج المذكورة اعلاه يتم رفض الفرضية.

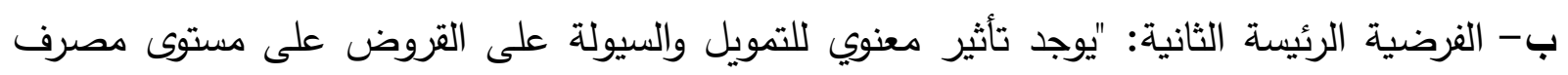

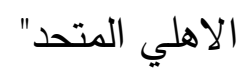
ان قيمة (f) المحسوبة والتي تقيس معنوية نموذج الانحدار البسيط كانت اعلى من الجدولية وهي (79, ؟ )

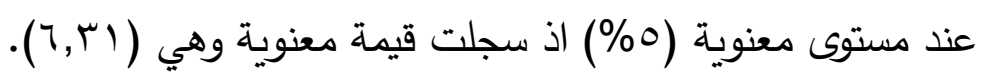

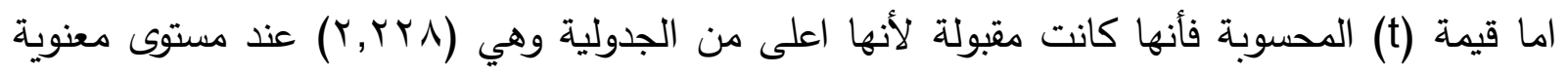

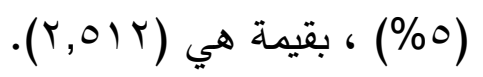

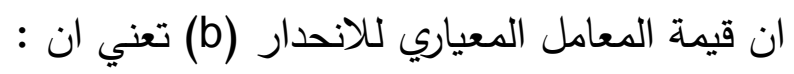

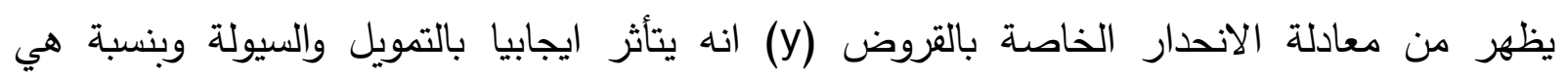
$(\% \varepsilon \cdot, 7)$

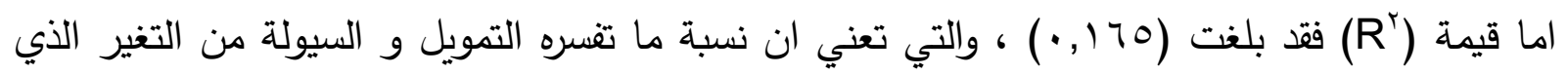

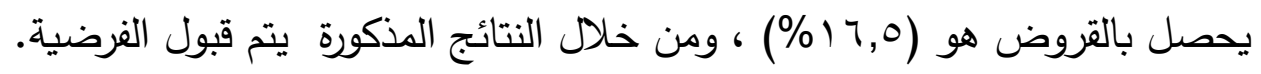

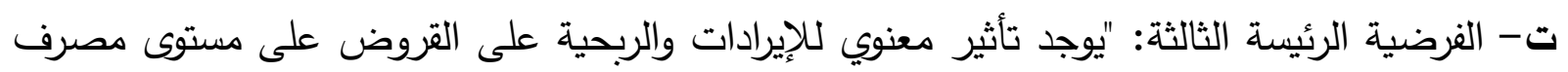

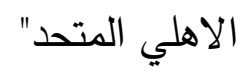
ان قيمة (f) المحسوبة والتي تقيس معنوية نموذج الانحدار البسيط كانت اعلى من الجدولية وهي (79, ؟ )

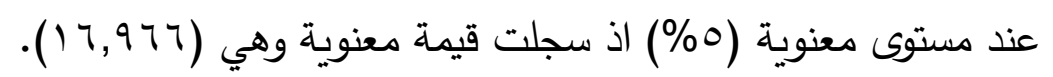

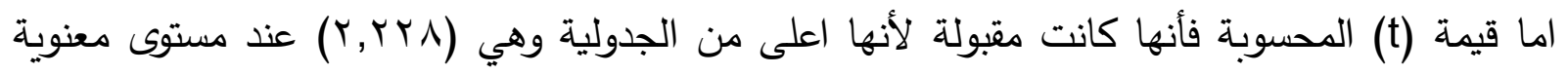

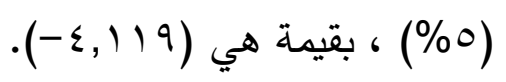


إن قيمة المعامل المعياري للانحدار (b) تعني ان: يظهر من معادلة الانحدار الخاصة بالقروض (y) انه يتأثر عكسيا بالإيرادات والربحية وبنسبة هي أنيات $(\% \wedge \varepsilon, r)$

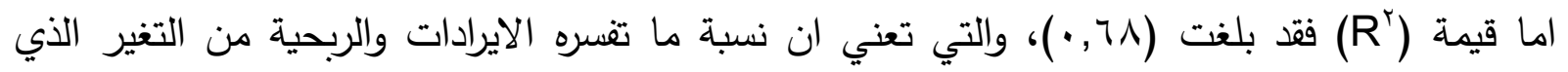

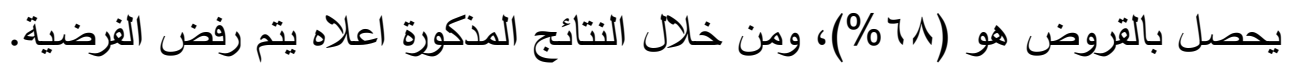
ث- الفرضية الرئيسة الرابعة: "يوجد تأثير معنوي لراس المال والرفع المالي على القروض على مستوى رفي مصرف الاهلي المتحد" ان قيمة (f) المحسوبة والتي تقيس معنوية نموذج الانحدار البسيط كانت اقل من الجدولية وهي (79, §) عند مستوى معنوية (0\%) اذ سجلت قيمة غير معنوية وهي (T) (, , ·) وهي غير معنوية.

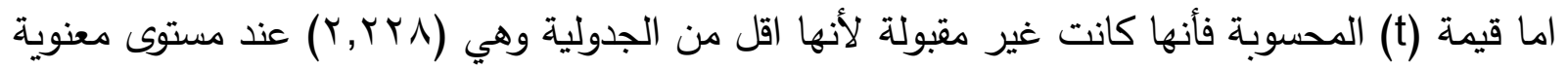

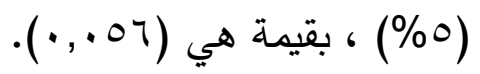

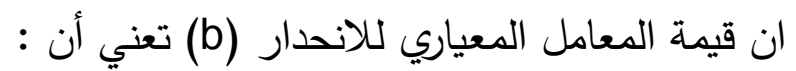

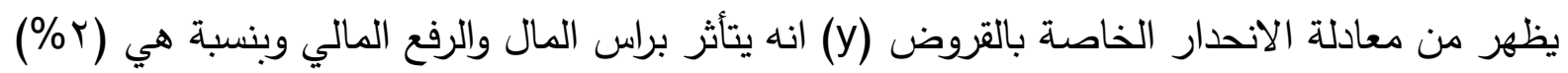

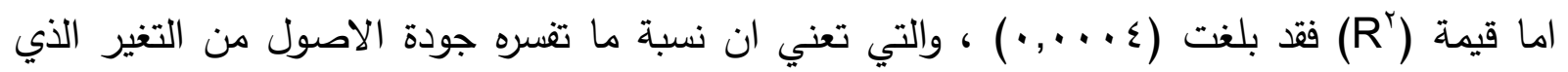
يحصل بالقروض هو (ع •, • \%) ، و من خلال النتائج المذكورة اعلاه يتم رفض الفرضية.

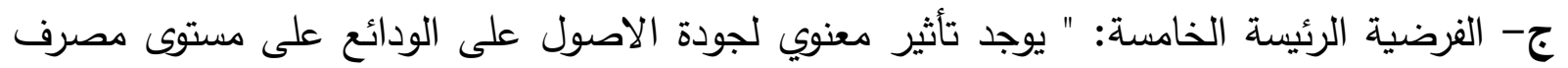

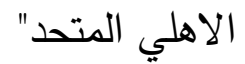

إن قيمة (f) المحسوبة والتي تقيس معنوية نموذج الانحدار البسيط كانت اقل من الجدولية وهي (79, ؟) عند مستوى معنوية (0\%) اذ سجلت قيمة غير معنوية وهي (T ب +, •).

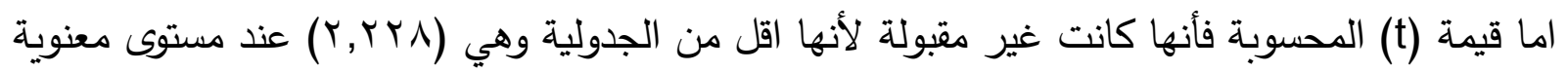
(\%) ، بقيمة هي (7 1, • (). 


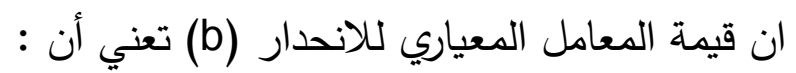

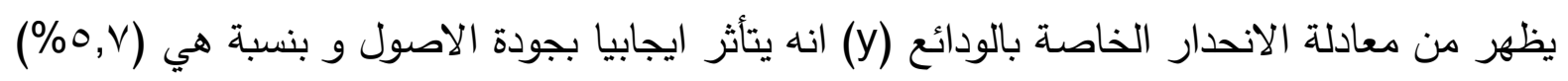

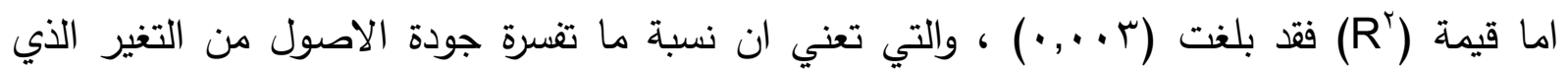

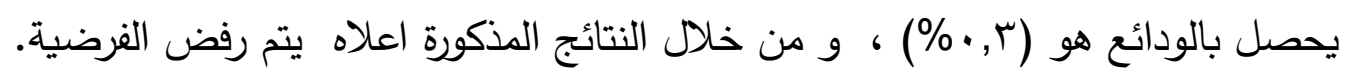

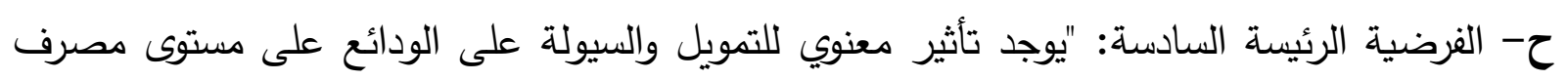
الاهلي المتحد" - ماته ان قيمة (f) المحسوبة والتي تقيس معنوية نموذج الانحدار البسيط كانت اعلى من الجدولية وهي (79, ؟ ) عند مستوى معنوية (0\%) اذ سجلت قيمة معنوية وهي (1) (1) (1) ).

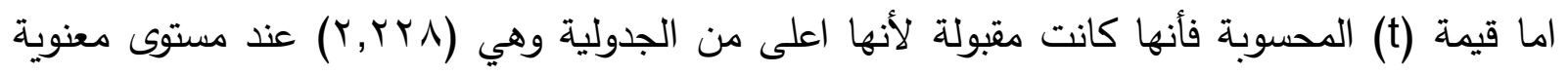

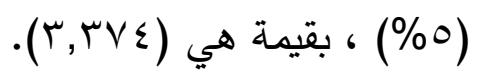

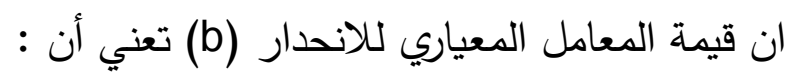

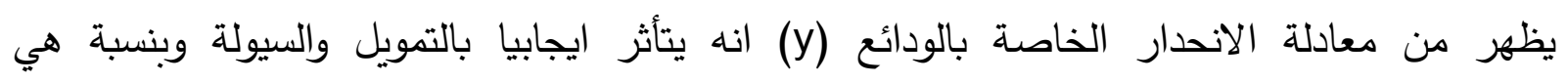
$(\% 01, r)$

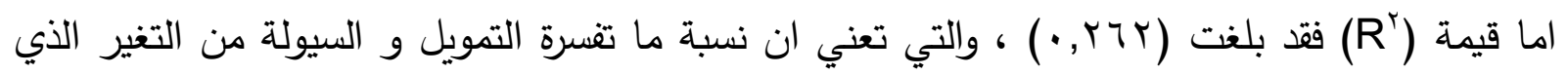

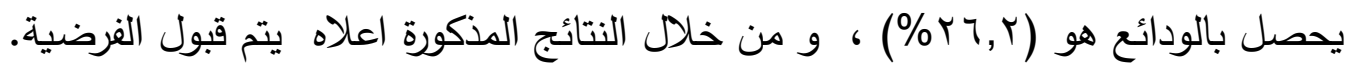

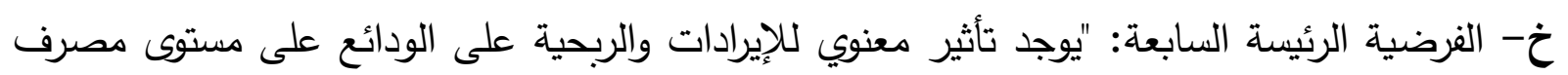

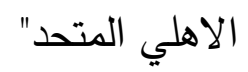

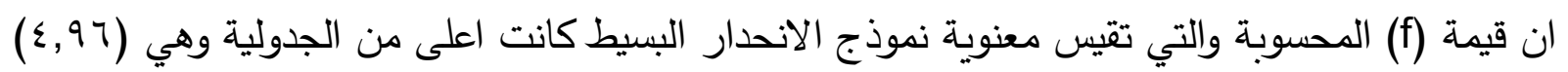

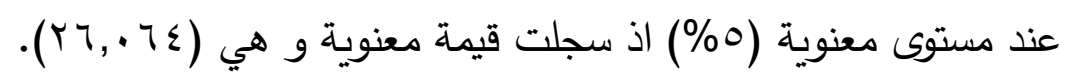

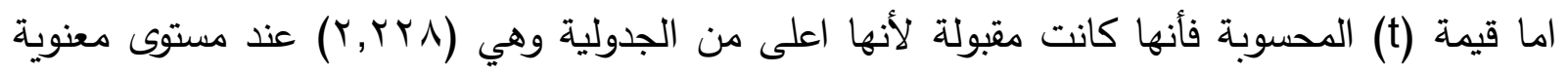

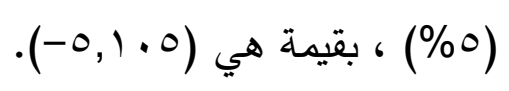


ان قيمة المعامل المعياري للانحدار (b) تعني ان : يظهر من معادلة الانحدار الخاصة بالودائع (y) انه يتأثر عكسيا بالإيرادات والربحية وبنسبة هي تعلي $(\% \wedge \vee, 0)$

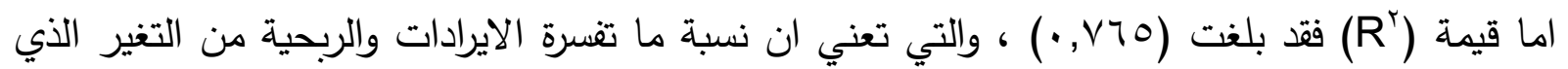
يحصل بالودائع هو (K>7,0\%) ، و و من خلال النتائج المذكورة اعلاه يتم قبول الفرضية. د- الفرضية الرئيسة الثامنة: "يوجد تأثير معنوي لراس المال والرفع المالي على الودائع على مستوى لـن مصرف الاهلي المتحد" ان قيمة (f) المحسوبة والتي تقيس معنوية نموذج الانحدار البسيط كانت اقل من الجدولية وهي (79, §)

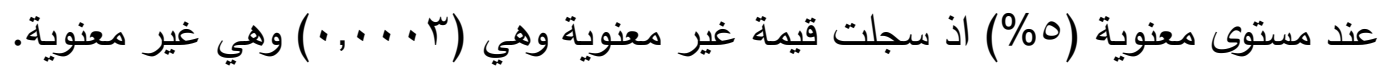

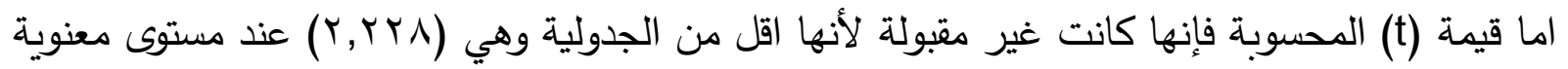

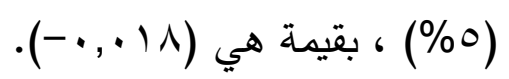

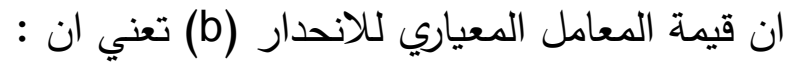
يظهر من معادلة الانحدار الخاصة بالودائع (y) انه يتأثر عكسيا براس المال والرفع المالي وبنسبة هي $(\% \cdot, 7)$

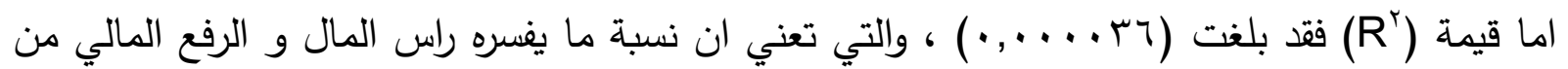

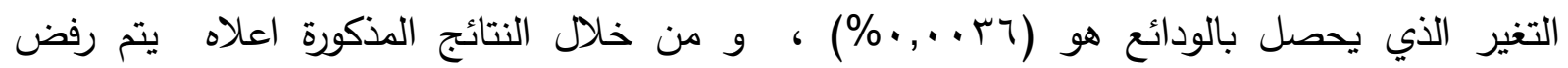
الفرضية. 


\section{التصنيف الائتهاني لوكالة فيتش ودوره في منح القروض وجذب الودائع}

جدول (T؟) اختبار فرضيات التأثير لمصرف الاهلي المتحد

\begin{tabular}{|c|c|c|c|c|c|c|c|c|}
\hline النتيجة & المعنوية & التابع & $R^{r}$ & $\begin{array}{c}\text { F } \\
\text { المحسوبة }\end{array}$ & $\begin{array}{c}\text { T } \\
\text { المحسوبة }\end{array}$ & $\beta$ & $\alpha$ & المستقل \\
\hline رفض & معنوية & $Y_{11}$ & $\cdot, \cdot r$ & $\cdot, \cdot 1 \leq$ & $-\cdot, \cdot 1 r$ & $-\cdot, \cdot \leq r$ & $Y Y T \cdot \neg T \Lambda, V Y \varepsilon$ & $X_{11}$ \\
\hline قبول & معنوية & $Y_{11}$ &., 170 & $7, \Gamma$ & $r, 01 Y$ & $\cdot, \varepsilon \cdot 7$ & NONYAr, 199 & $X_{1 r}$ \\
\hline ق ق قبول & معنوية & $Y_{11}$ & $\cdot, 7 \wedge$ & 17,977 & $-\varepsilon, 119$ & $-\cdot, \wedge \leq Y$ & $\varepsilon \cdot V \cdot 90 r, 0 r$. & $X_{1 r}$ \\
\hline رفض & غعنوية & $Y_{11}$ & $\cdot, \cdots \varepsilon$ & $\cdot, \cdot r$ &., .07 & $\cdot, \cdot r$ & rIY107r,Tro & $X_{1 \varepsilon}$ \\
\hline رفض & غعنوية & $Y_{i r}$ & $\cdot, \cdots r$ & $\cdot, \cdot r t$ & $\cdot, 17$ &., $.0 \mathrm{~V}$ & $r \vee \leqslant \vee r \wedge T, q Y 0$ & $X_{11}$ \\
\hline قبول & معنوية & $Y_{i r}$ & $\cdot, r T Y$ & $11, \mathrm{r}$ & $r, T V \varepsilon$ &., $01 \mathrm{r}$ & qqrrqr,TVr & $X_{1,}$ \\
\hline ق قبول & معنوية & $Y_{i r}$ & $\cdot, \vee \vee 70$ & YT, $T \leq$ & $-0,1 \cdot 0$ & $-\cdot, \wedge \vee 0$ & $\leqslant \wedge 9 \wedge \wedge \leqslant 9, \leqslant \vee \leqslant$ & $X_{1 r}$ \\
\hline رفض & غعنوية & $Y_{i r}$ & דו"., & •, , ., & $-\cdot, \cdot 11$ & $-\cdot, \ldots 7$ & 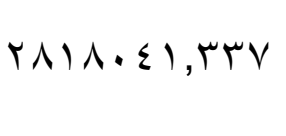 & $X_{1 \varepsilon}$ \\
\hline
\end{tabular}

SPSS V.Y المصدر : اعداد الباحث بالاعتماد على مخرجات برنامج

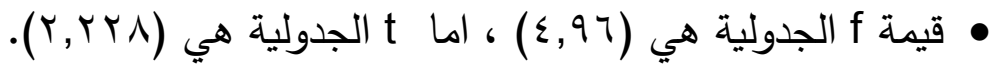


الاستنتاجات والتوصيات:

أولا: الاستنتاجات:

1. أظهرت نتائج الاحصاء الوصفي وجود علاقة طردية ما بين التصنيف الائماني كمتغير مستقل، والقروض والودائع المصرفية كمتغير تابع لمصرف الاهلي المتحد .. r. ان لمؤشر جودة الاصول، تأثير غير معنوي في مصرف العابع الاهلي المتحد .

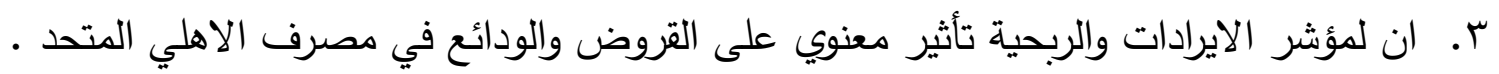

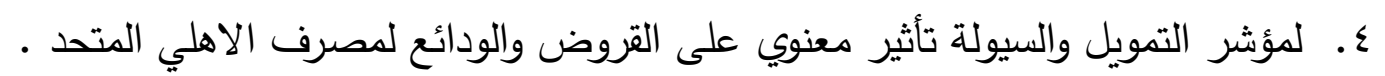
ه. لمؤشر رأس المال والرفع المالي تأثير غير معنوي على القيري على القروض والودائع لمصرف الاهلي المتحد . التوصيات:

ا. ضرورة حصول المصارف العامة والخاصة على التصنيف الائتماني من قبل وكالات التصنيف الائتماني العالمية ، من اجل تطبيق مقررات لجنة بازل ب ، وتحديد نقاظ القوة التي تتمتع بها المصارف لتصن ونقاط الضعف التي تعاني منها. r. وضع قوانين وتشريعات توضح تعامل المصارف والمؤسسات مع وكالات التصنيف الأتتماني العالمية ، و الحصول على درجة التصنيف الأيتماني. r.نوصي المصارف العراقية باستخدام التصنيف الائتماني لكونه معتمداً عالمياً، والذي تقوم به وكالات تصنيف ذات مقبولية دولية . ع. إثاعة ثقافة التصنيف الأتماني في الهيكل التنظيمي بمختلف وحداته واقسامه بالمصرف، وكذلك

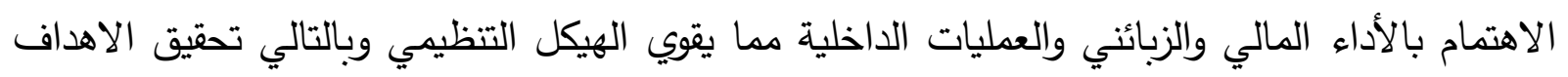

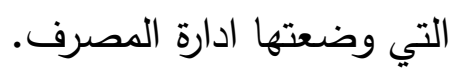


a-Messages and atarih 1-An-Ping Lin 6 . 10 ، Management Earnings Guidance and Future Credit Rating Agency Actions ،A Dissertation Presented in Partial Fulfillment ،ARIZONA STATE UNIVERSITY. b-Research and reports 1-Standard \& Poors "Sovereign Government Rating Methodology and Assumption " the McGraw- Hill , NY, r. ll.

r-Joyce Michel Mounayar, "Credit Risk: The Major Determinations of Credit Risk Ratings", American University of Beirut, Beirut, $Y_{\ldots} \ldots$, .

$r$-Fitch Ratings, "Definitions of Ratings and Other Scales", Fitch Ratings, NY, r . १.

$\varepsilon-$ Ratings- Definitions of Ratings and Other Forms of Opinion - Jan $r_{.}, \varepsilon$.

--Amanda J. Bahena, What Role Did Credit Rating Agencies Play in the Credit Crisis?, r.1.

7-The Reform of the Credit Rating Agencies: A Comparative Perspective Piero Cinquegrana $r_{\text {... }}$.

$\checkmark-$ Fitch Ratings Definitions of Ratings and Other Forms of Opinion $r \cdot 1 \wedge$. 
